\title{
Anti-Gastric Cancer Effect of Purified Omphalia Lapidescens Protein via Regulating the JAK/STAT3 Signaling Pathway
}

\section{Wenjun Xu}

Zhejiang Chinese Medical University

\section{Zhongxia Lu}

Ocean University of China

\author{
Man Hei Cheung \\ Hong Kong University of Science and Technology \\ Yuqin $\mathrm{Xu}$ \\ Zhejiang Chinese Medical University \\ Meiai Lin \\ Zhejiang Chinese Medical University \\ Chun Liang \\ Hong Kong University of Science and Technology \\ Jianshu Lou \\ Hangzhou Normal University \\ Yitao Chen ( $\nabla$ cytworld@163.com ) \\ Zhejiang Chinese Medical University
}

\section{Research Article}

Keywords: Gastric cancer, JAK/STAT3, microarray, pPeOp, KEGG

Posted Date: December 14th, 2020

DOl: https://doi.org/10.21203/rs.3.rs-113262/v1

License: (c) (1) This work is licensed under a Creative Commons Attribution 4.0 International License. Read Full License 
Title Page

Manuscript category: ORIGINAL ARTICLE

Manuscript title: Anti-gastric cancer effect of purified Omphalia lapidescens protein via regulating the JAK/STAT3 signaling pathway

Running title: Effect of $\mathrm{pPeOp}$ on gastric cancer cells

\section{Authors information:}

Wenjun $\mathrm{Xu}^{1+}$, Zhongxia $\mathrm{Lu}^{1,3+}$, Man Hei Cheung ${ }^{2+}$, Yuqin $\mathrm{Xu}^{1}$, Meiai Lin ${ }^{1}$, Chun Liang $^{2,5^{*}}$, Jianshu Lou ${ }^{4 *}$, Yitao Chen ${ }^{1,2 *}$

${ }^{1}$ College of Life Science, Zhejiang Chinese Medical University, Hangzhou, China;

${ }^{2}$ Division of Life Science, Center for Cancer Research and State Key Lab for Molecular Neural Science, The Hong Kong University of Science and Technology, Hong Kong, China;

${ }^{3}$ School of Medicine and Pharmacy, Ocean University of China, QingDao, China;

${ }^{4}$ Key Laboratory of Elemene Class Anti-cancer Chinese Medicine of Zhejiang Province, Holistic Integrative Pharmacy Institutes, School of medicine, Hangzhou Normal University, Hangzhou, China;

${ }^{5}$ EnKang Pharmaceuticals (Guangzhou), Ltd., Guangzhou, China.

${ }^{+}$Contributed equally.

${ }^{*}$ These authors are co-corresponding author.

Yitao Chen will handle the production process.

Correspondence to: Professor Yitao Chen, College of Life Science, Zhejiang Chinese Medical University, Hangzhou, China. Email address: cytworld@163.com. 


\section{Author: Wenjun Xu}

Affiliations: College of Life Science, Zhejiang Chinese Medical University, Hangzhou 310053, China.

Address: No. 548 Binwen Road, Binjiang District, Zhejiang Chinese Medical University, Hangzhou 310053, China.

Tel: +86-15988828396; Fax: +86-571-86613600.

E-mail: 15988828396@163.com

\section{Author: Zhongxia Lu}

Affiliations: College of Life Science, Zhejiang Chinese Medical University, Hangzhou 310053, China.

School of Medicine and Pharmacy, Ocean University of China, QingDao 266003, China.

Address: No. 548 Binwen Road, Binjiang District, Zhejiang Chinese Medical University, Hangzhou 310053, China.

Tel: +86-18158507989; Fax: +86-571-86613600.

E-mail: 18158507989@163.com

\section{Author: Man Hei Cheung}

Affiliations: Division of Life Science, Center for Cancer Research and State Key Lab for Molecular Neural Science, Hong Kong University of Science and Technology, 
Hong Kong, China.

Address: The Hong Kong University of Science and Technology Clear Water Bay, Kowloon, Hong Kong, China.

Fax: $+86-571-86613600$.

E-mail: mhcheungac@connect.ust.hk

\section{Author: Yuqin Xu}

Affiliations: College of Life Science, Zhejiang Chinese Medical University, Hangzhou 310053, China.

Address: No. 548 Binwen Road, Binjiang District, Zhejiang Chinese Medical University, Hangzhou 310053, China.

Tel: +86-15757303616; Fax: +86-571-86613600.

E-mail: 15757303616@163.com

\section{Author: Meiai Lin}

Affiliations: The Second Clinical Medical College, Zhejiang Chinese Medical University, Hangzhou 310053, China.

Address: No. 548 Binwen Road, Binjiang District, Zhejiang Chinese Medical University, Hangzhou 310053, China.

Tel: +86-15868866086; Fax: +86-571-86613600. 
E-mail:1ma@zcmu.edu.cn

\section{*Corresponding authors: Chun Liang}

Affiliations: Division of Life Science, Center for Cancer Research and State Key Lab for Molecular Neural Science, Hong Kong University of Science and Technology, Hong Kong, China.

Intelgen (Hong Kong-Guangzhou-Foshan) Limited, China.

Address: The Hong Kong University of Science and Technology Clear Water Bay, Kowloon, Hong Kong, China.

E-mail addresses: bccliang@ust.hk

\section{*Corresponding author: Jianshu Lou}

Affiliations: Holistic Integrative Pharmacy Institutes, School of medicine, Hangzhou Normal University, Hangzhou 311121, China.

Key Laboratory of Elemene Class Anti-cancer Chinese Medicine of Zhejiang Province, Holistic Integrative Pharmacy Institutes, School of medicine, Hangzhou Normal University.

Address: No. 2318 Yuhangtang Road, Yuhang District, Hangzhou city, Hangzhou Normal University, China.

Tel: +86-571-86633051; Fax: +86-571-86613600.

E-mail: jlouab@connect.ust.hk 


\section{"Corresponding author: Yitao Chen}

Affiliations: College of Life Science, Zhejiang Chinese Medical University, Hangzhou 310053, China.

Division of Life Science, Center for Cancer Research and State Key Lab for Molecular Neural Science, Hong Kong University of Science and Technology, Hong Kong, China.

Address: No. 548 Binwen Road, Binjiang District, Zhejiang Chinese Medical University, Hangzhou 310053, China.

Tel: +86-571-86633051; Fax: +86-571-86613600.

E-mail: cytworld@163.com

${ }^{+}$These authors contributed equally to this work.

${ }^{*}$ These authors are co-corresponding author.

Yitao Chen will handle the production process.

Abbreviations: O.lapidescens, Omphalia lapidescens; pPeOp, purified Omphalia lapidescens protein; RPMI-1640, Roswell Park Memorial Institute (RPMI) 1640; RT-qPCR, reverse transcription quantitative polymerase chain reaction; PVP, polyvinylpyrrolidone; GC, gastric cancer; GO, Gene Ontology; KEGG, Kyoto Encyclopedia of Genes and Genomes; PVDF, polyvinylidene fluoride; DEGs, Differentially expressed genes; NC, negative control; KD, knock down.

\section{Abstract}


Background: Gastric cancer is the leading cause of cancer-related death worldwide. The aim of present study was to investigate the anti-tumor effect of purified Omphalia lapidescens protein $(\mathrm{pPe} O \mathrm{p})$ in gastric cancer.

Methods: Microarray analysis was performed to find out differentially expressed genes in pPeOp-treated $\mathrm{MC}-4$ gastric cancer cells. The Janus kinase (JAK)/signal transducer and activator of transcription (STAT) 3 signaling pathway was most likely to be altered after bioinformatics analysis. Interleukin-6 (IL-6) and NSC74859 were used as the agonist and inhibitor of the JAK/STAT3 signaling pathway, respectively. Flow cytometry and MTS assay were used for cell proliferation and viability analysis in pPeOp-treated gastric cell lines with IL-6 or NSC74859.

Results: The anti-tumor effect was increased when pPe $O$ p were co-treated with IL-6, while decreased in inhibitor treatment. The expression of the crucial members in the pathway of MC-4 cells, including glycoprotein 130 (GP130), JAK1, JAK2, STAT3, p-STAT3, suppressor of cytokine signaling SOCS1 and SOCS3, was investigated by western blotting.

Conclusion: $\mathrm{pPe} O \mathrm{p}$ exhibited promising anticancer effect in the xenograft nude mice model, established by STAT3 knock down gastric cancer cells. Thus, JAK/STAT3 inhibition partially contributed to the anticancer effect of $\mathrm{pPe} O \mathrm{p}$, which may serve as a novel strategy for gastric cancer.

Key words: Gastric cancer, JAK/STAT3, microarray, pPeOp, KEGG

\section{Background}

Gastric cancer (GC), the third most common malignancy worldwide [1-3]. Although multimodal treatments, including surgery, chemotherapy, and radiotherapy, have improved, patients with GC still have poor prognosis [4]. Therefore, it is essential to find an effective alternative to traditional treatment for gastric cancer with fewer side effects.

Omphalia lapidescens, one of the most important medical fungi in traditional 
Chinese medicine, has been reported to possess anti-tumor properties [5-6]. pPeOp is a protein extracted from O.lapidescens with PVP extraction buffer [7]. Previous studies demonstrated that $\mathrm{pPe} O \mathrm{p}$ suppresses metastasis, arrests cell cycle and induces apoptosis in MC-4 gastric cancer cells without causing toxicity to MC-1 normal gastric cells [8]. Thus, the underlying anti-tumor mechanism of $\mathrm{pPeOp}$ deserves further research.

In the present study, we identified differentially expressed genes (DEGs) and regulated signaling pathways via expression profile chip in human gastric cancer MC-4 cells. The JAK/STAT3 signaling pathway is most likely to be regulated. Appropriate concentrations of the agonists (IL-6) and inhibitors (NSC74859) of the JAK/STAT3 signaling pathway were determined by RT-qPCR and MTS assay. Flow cytometry and MTS assay were used to investigate the effects of IL-6 and NSC74859 on the DNA content of different phase cells and viability after $\mathrm{pPe} O \mathrm{p}$ intervention. Western blotting was applied to observe the effect of $\mathrm{pPe} O \mathrm{p}$ on the regulation of the JAK/STAT3 signaling pathway in the absence or presence of IL-6 or NSC74859. Furthermore, the anticancer effect of $\mathrm{pPe} O \mathrm{p}$ was determined by xenograft nude mice models which were established by wild-type MC-4 and STAT3 knockdown MC-4 cells.

\section{Methods}

Reagents and Chemicals

The fruiting body of $O$. lapidescens was purchased from Fang Hui Chun Tang (Hangzhou, China). Based upon our preliminary study, $\mathrm{pPe} O \mathrm{p}$ is a newly discovered bioactive protein with anti-tumor activity in $O$. lapidescens. It was a purified bioactive protein in O. lapidescens which was obtained using polyvinylpyrrolidone (PVP) followed by gel fltration chromatography. The methods of extraction and purifcation with $O$. lapidescens have been proved by previous experiments [7].

RPMI-1640 was provided from Genom Biomedical company (Cas No.31800, Hangzhou, China). TRIzol used in RNA extraction was provided from Thermo Fisher 
Scientific (cat. no. 15506-026, USA). Recombinant human IL-6 was purchased from Beyotime (cat. no. P5138-100 $\mu \mathrm{g}$, Shanghai, China). NSC74859 was purchased from MedChemExpress (cat. no. 501919-59-1, USA). Primers were purchased from Sangon Biological Technology (Shanghai, China). Reagents regarding microarray were provided by Capital-Bio Technology (Beijing, China). All antibodies including GP130, JAK1, JAK2, STAT3, p-STAT3, SOCS1 and SOCS3 were purchased from Cell Signaling Technology (Boston, USA).

\section{Cell Culture}

The human normal gastric cell line MC-1 and human gastric cancer cell lines MC-4, which had been reported at previous study [8], were provided from Zhejiang Provincial Center for Disease and Prevention Centre (Zhejiang CDC). Human normal gastric cell line MC-1 and human gastric cancer cells were cultured with RPMI-1640 medium with 5\% (v/v) fetal bovine serum (Gibco®), $100 \mathrm{U} / \mathrm{ml}$ penicillin and 100 $\mathrm{U} / \mathrm{ml}$ streptomycin in a humidified $5 \% \mathrm{CO}_{2}$ atmosphere at $37{ }^{\circ} \mathrm{C}$.

\section{Microarray Data Assay}

When MC-4 cells density reached 80\%, pPeOp-treated group was treated with 60

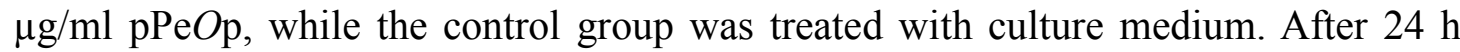
treatment, total RNA was extracted using the TRIzol reagent. The concentration and quality of RNA were determined by NanoDrop (ND-1000, NanoDrop Technologies, Wilmington, DE, USA). RNA was hybridized to an Affymetrix 3'IVT microarray (Affymetrix, California, USA). Differentially expressed genes (DEGs) were identified with a $>$ 4-fold differential expression, and changes of gene expression were considering significant.

\section{Gene Ontology (GO) and KEGG Pathway Enrichment Analysis}


In order to explore the potential biological functions and involved signaling pathways of the DEGs, GO and KEGG were employed for analysis. There are three categories in GO platform namely biological process (BP), molecular function (MF), and cellular component (CC) [9]. The significance of GO enrichment was set to a cut-off P value of 0.05 . The KEGG was applied to investigate multiple pathways in which the DEGs are involved. The top 10 pathways were regarded as signaling pathways that are potentially related to $\mathrm{pPe} O \mathrm{p}$-treatment.

\section{Reverse Transcription-Quantitative PCR Analysis(RT-qPCR)}

RT-qPCR was used to validate the microarray data. Total RNA was extracted with TRIzol reagent (Invitrogen; Thermo Fisher Scientific, Inc., Waltham, MA, USA). According to the manufacturer's protocol, cDNA was synthesized using a Maxima First Strand cDNA Synthesis kit (cat. no. K1672, Thermo Fisher Scientific, Inc.). Primers were purchased from Shanghai Sangon Biological Engineering Technology (Shanghai, China), of which the GAPDH former primer was 5'TGACTTCAACAGCGACACCCA3', the downstream primer was

5'CACCCTGTTGCTGTAGCCAAA3'. The primer sequences for genes in JAK/STAT3 signal pathway included the following: GP130 forward, 5'TAGTGACCAGCAGTTATAT3' and reverse, 5'CGACTACAGTGTCAAATAA3'; JAK1 forward, 5'CCTGCTGGTGGCTACTAAGA3' and reverse, 5'AGATGTGTGTTCTCGTGCCT3'; and the former primer of JAK2 forward was 5'GCCTTCTTTCAGAGCCATCA3' and reverse, 5'CCAGGGCACCTATCCTCATA3'; and STAT3 forward was 5'GACATGGAGTTGACCTCGGAGTG3', and reverse, 5'GGTGGCAGAATGCAGGTAGGC3'; the former primer of SOCS1 was 5'TCGCCCTTAGCGTGAAGA3', the downstream primer was 5'CTGCCATCCAGGTGAAAGC3'; the former primer of SOCS3 was 5'GCCACTCTTCAGCATCTCT3', the downstream primer was 5'GGTCCAGGAACTCCCGAAT3'. The PCR was carried out with SYBR-Green Master Mix (cat. no. A25741, Thermo Fisher Scientific, Inc.) by a Eppendorf 
Realplex-4 Real Time PCR Machine (Eppendorf, Hamburg, Germany) following the instructions of the manufacturer. The comparative cycle threshold $(\mathrm{Cq})(\Delta \Delta \mathrm{Cq})$ method was used to analyze the data [10]. The expression data for each sample were normalized to GAPDH.

\section{Western Blotting}

Cells $\left(5 \times 10^{5}\right)$ were lysed with lysis buffer (Beyotime Biotechnology, Shanghai, China) for $30 \mathrm{~min}$ on ice. The lysates were clarified by centrifugation at $4{ }^{\circ} \mathrm{C}$ for $15 \mathrm{~min}$ at $12,000 \mathrm{~g}$. Total protein concentration in the supernatants was detected by BCA Protein Assay kit (cat. no. PC0020, Solarbio life science, China). The cell lysates were boiled in SDS-PAGE sample buffer. Protein samples $(40 \mu \mathrm{g})$ were resolved by SDS-PAGE, transferred onto PVDF membranes (Immobilon (®)-FL membrane, Millipore Company, Massachusetts, USA) and blocked with skim milk for $2 \mathrm{~h}$ at room temperature. The membrane was then incubated with rabbit antibodies against GP130 (1:1,000; cat. no. 3732; CST), JAK1 (1:1,000; cat. no. 3344; CST), JAK2 (1:1,000; cat. no. 3230; CST), p-STAT3 (1:1,000; cat. no. 9145; CST), STAT3 (1:1,000; cat. no. 12640; CST), SOCS1 (1:1,000; cat. no. 3950; CST) and SOCS3 (1:1,000; cat. no. 52113; CST) overnight at $4{ }^{\circ} \mathrm{C}$. Membranes were washed three times with TBST and incubated with HRP-conjugated goat anti-rabbit IgG (cat. no. P0018AS; Beyotime Biotechnology, China) for $2 \mathrm{~h}$. Then, membranes were washed three times with TBST. Blots were detected by ECL STAR luminous solution (cat. no. A0208; Beyotime Biotechnology, China) with an Aplegen Gel Documentation System (OmegaLum G, San Francisco, USA).

\section{Flow Cytometry}

Cells $\left(5 \times 10^{5}\right)$ were seeded in 6-well plate and cultured with L-Mimosine $(50 \mathrm{mM}$; cat. no. M0253; Sigma) for $24 \mathrm{~h}$ at $37^{\circ} \mathrm{C}$. Then, cells were treated with culture medium, pPeOp $(60 \mu \mathrm{g} / \mathrm{ml}), \mathrm{IL}-6(100 \mathrm{ng} / \mathrm{ml}), \mathrm{pPe} O \mathrm{p}(60 \mu \mathrm{g} / \mathrm{ml})$ and IL-6 (100 ng/ml), 
NSC74859 $(100 \mathrm{ng} / \mathrm{ml}), \mathrm{pPeOp}(60 \mu \mathrm{g} / \mathrm{ml})$ and NSC74859 $(100 \mathrm{ng} / \mathrm{ml})$ for $24 \mathrm{~h}$, respectively. Cultured cells were harvested with EDTA-free trypsin $(0.25 \%)$ and washed twice with ice-cold PBS. For cell cycle analysis, cells were fixed with $1 \%$ paraformaldehyde at $25{ }^{\circ} \mathrm{C}$ for $30 \mathrm{~min}$, stored in $70 \%$ ethanol at $-20{ }^{\circ} \mathrm{C}$ for $15 \mathrm{~min}$ and incubated with $0.5 \mathrm{ml}$ of propidium iodide (PI)/RNase staining buffer for $15 \mathrm{~min}$ at room temperature. Samples were analyzed using a Beckman FC500.

\section{MTS assay}

Cells were inoculated on 96-well plate at a density of $2 \times 10^{4}$ cells per well and cultured with L-Mimosine $(50 \mathrm{mM})$ for $24 \mathrm{~h}$ at $37{ }^{\circ} \mathrm{C}$. Subsequently, cells were treated with culture medium, pPe $O \mathrm{p}(60 \mu \mathrm{g} / \mathrm{ml})$, IL-6 (100 ng/ml), pPe $O \mathrm{p}(60 \mu \mathrm{g} / \mathrm{ml})$ and IL-6 (100 ng/ml), NSC74859 (100 ng/ml), pPeOp $(60 \mu \mathrm{g} / \mathrm{ml})$ and NSC74859 (100 ng/ml) for $24 \mathrm{~h}$, respectively. $20 \mu \mathrm{l}$ MTS (Promega Corporation) were added to each well, agitated lightly for $30 \mathrm{~s}$, and then incubated for $2 \mathrm{~h}$ at $37^{\circ} \mathrm{C}$ in the dark. The optical density (OD) was measured at $490 \mathrm{~nm}$ using a microplate reader (Labsystems).

\section{Lentivirus Transduction}

The lentiviruses, including STAT3 knock down lentiviruses (LV-STAT3-GFP) and the null vector (LV-GFP), were purchased from GeneChem Corporation (Shanghai, China). MC-4 cells $\left(1 \times 10^{5}\right)$ were inoculated onto a 6-well plate. According to the standard protocol, $5 \mu \mathrm{g} / \mathrm{ml}$ polybrene (Sigma-Aldrich, St Louis, USA), dissolved in culture medium, was mixed and incubated for $4 \mathrm{~h}$. Then, lentivirus $(5 \mu \mathrm{l})$ was added individually to the wells and mixed gently. After $9 \mathrm{~h}$ of infection, the medium containing the lentivirus was replaced with normal medium and cultured for another 48 h. The transduction efficiency was observed under a Leica DMIRE inverted fluorescence microscope system (Leica Microsystems Corp), and the knockdown efficiency of STAT3 was quantified by western blotting and RT-qPCR. 


\section{Animals and Grouping}

Female BALB/c nude mice, 5 weeks old, were purchased from Shanghai Linchang Biotechology Corporation (Shanghai, China). All animal experiments were carried out in Shanghai GeneChem Corporation experimental center (rodent license SCXK (Shanghai) 2013-0018). Mice were housed at $25^{\circ} \mathrm{C}$ with $50-70 \%$ humidity and a $12 \mathrm{~h}$ light/12 $\mathrm{h}$ dark cycle with free access to food and water according to the standard protocol. This study was approved by the Ethics Committee of Shanghai GeneChem Corporation (No. GSZE88644).

All animals were randomly divided into 3 groups, 20 mice in each group. Xenograft nude mice model was established by implanting wild type MC-4 cells, LV-GFP MC-4 cells or LV-STAT3-GFP (STAT3 knockdown) MC-4 cells. After 2 weeks, half of the animals in each group (10 nude mice) were treated with PVP $(10 \mathrm{mg} / \mathrm{kg})$, and the remaining half treated with $\mathrm{pPe} O \mathrm{p}(10 \mathrm{mg} / \mathrm{kg})$ by caudal vein injection every 5 days. 7 days after tumor formation, the tumor volume and weight were detected and recorded following the treatment. Before the end of the experiment, the live imaging of nude mice was detected with Lumina LT animal living imaging system (Perkin Elmer, American) after intraperitoneal injection of D-Luciferin $(15 \mathrm{mg} / \mathrm{ml})$. The sizes of the resulting subcutaneous xenografts were monitored by measuring the tumor length (L) and width (W). The tumor volume was calculated using the formula: Volume $=0.5 \times\left(\mathrm{L} \mathrm{x} \mathrm{W}^{2}\right)$. Finally, all mice were sacrificed by $\mathrm{CO}_{2}$ asphyxiation and the tumor was dissected for the following experiment. The tumor inhibition rate (IR) according to the following formula:

$$
\operatorname{IR}(\%)=(1-\mathrm{W} / \mathrm{W}) \times 100 \%
$$

Where, $\mathrm{w}$ is the average tumor weight in the treatment group and $\mathrm{W}$ is the average tumor weight in the control group.

\section{Statistical Analysis}


Data were expressed as the mean \pm standard deviation (SD). SPSS 16.0 software (version 20.0; IBM Corp., Armonk, NY, USA) was used for statistical analyses. Western blotting results were quantified by Image $\mathbf{J}$ (version 1.8.0; National Institutes of Health, Bethesda, MA, USA) and analyzed by one-way ANOVA, followed by Fisher's least significant difference (LSD) post-hoc test. The MTS cell viability data and flowing cytometry results were performed using one-way analysis of variance (ANOVA) followed by Fisher's LSD post-hoc test. $\mathrm{P}<0.05$ was considered to indicate a statistically significant difference.

\section{Results}

\section{Identification of Differentially Expressed Genes}

The gene expression data in our manuscript has been deposited in Gene Expression Omnibus (GEO) (accession number: GSE141914). Differentially expressed genes (DEGs) were identified as those with $\mathrm{pPe} O \mathrm{p} / \mathrm{Normal} \geq 4$, which were considered to be up-regulated while those expressed with $\mathrm{pPeOp} / \mathrm{Normal} \leq 0.25$ were considered to be down-regulated. In total, 2066 genes were identified as DEGs, including 936 up-regulated and 1130 down-regulated genes.

\section{GO Analysis and KEGG Pathway Enrichment of DEGs}

To investigate the biological functions of the DEGs in pPeOp-treated $\mathrm{MC}-4$ cells, a GO analysis was performed. GO analysis revealed that these DEGs are related to various biological processes which play vital roles in cancer treatment, such as transcription (Fig. 1a), development and apoptosis. In terms of cellular component, nucleus, integral to membrane and cytoplasm are mostly regulated. The molecular functions associated with these DEGs include protein binding, zinc ion binding, metal ion binding, etc.

KEGG is an authoritative database, which contains numerous biochemical 
pathways [12]. Following KEGG enrichment analysis, significant KEGG terms were collected. The most significantly regulated pathway by pPeOp was the JAK/STAT3 signaling pathway $\left(\mathrm{P}=1.12 \times 10^{-11}\right)$. Besides, the MAPK signaling pathway, $\mathrm{B}$ cell receptor signaling pathway and the p53 signaling pathway were also being significantly regulated by pPeOp. Top $10 \mathrm{KEGG}$ enrichment results were presented (Fig. 1b).

\section{Validation of DEGs}

In order to validate our microarray findings, we chose the key nodes of the JAK/STAT3 signaling pathway (GP130, JAK1, JAK2, STAT3, SOCS1 and SOCS3) for further study in MC-4 cells. Results showed that the mRNA levels of GP130, JAK1, JAK2, STAT3 and protein levels of p-STAT3 were significantly decreased, whereas the mRNA expression levels of SOCS1 and SOCS3 were significantly elevated in MC-4 cells (Fig. 2a and b, respectively). Hence, the results were consistent with microarray findings.

\section{Optimum Concentration Screening of Agonist and Inhibitor}

MTS and RT-qPCR were used to determine the optimal concentrations of the agonist and inhibitor. In all cell lines (MC-4 gastric cancer cells and MC-1 gastric normal cells), the mRNA expression level of STAT3 and cell viability was significantly elevated after being treated with IL-6, whereas NSC74859 significantly attenuated expression levels of STAT3 (Fig. 3). Thus, $100 \mathrm{ng} / \mathrm{ml}$ of IL-6 was chosen as the most optimum concentration. NSC74859 at $100 \mathrm{ng} / \mathrm{ml}$ was selected for MC-1 and MC-4 for further study.

Effects of IL-6 and NSC74859 on Cell Viability and the DNA Content of Different Phase Cells after Treated with pPeOp 
In order to further study the role of JAK/STAT3 signal pathway in the anti-cancer of $\mathrm{pPe} O \mathrm{p}$, we studied the cell viability of gastric cells when inhibitor, agonist and $\mathrm{pPe} O \mathrm{p}$ acted together or alone. Cell viability reflects the percentage of cell survival after treatment [13]. As shown in Fig. 4a, in MC-4 cells, $70.20 \%$ cells suvival after treatment with $\mathrm{pPeOp}$ alone, that is, $29.80 \%(100 \%-70.20 \%)$ of cells were killed by pPeOp alone. 58.01\% (109.92\%-51.91\%), 27.10\% (80.60\%-53.50\%) of cells were inhibited by $\mathrm{pPeOp}$ in the combination with agonist or inhibitor, respectively. The results showed that $\mathrm{pPe} O \mathrm{p}$ significantly inhibited the activity of MC-4, and IL-6 significantly enhanced the inhibitory effect of $\mathrm{pPeOp}$ on the activity, whereas NSC74859 weaken the effect.

To further verify the above experimental data, flow cytometry was used to detect the DNA content and mortality under different treatments. DNA, as an important genetic material, degraded after cell death, thus cells in the Sub-G1 phase are regarded as dead cells [14]. $3.31 \%$ of total MC-4 cells were in Sub-G1 phase, $12.78 \%$ cells were in Sub-G1 phase after treated with pPeOp alone (Fig. 4c). MC-4 Cells in Sub-G1 phase were $1.98 \%$ and $18.78 \%$ after treated with IL-6 or act together with pPe $O$ p. In the group of inhibitor or co-treated with $\mathrm{pPe} O \mathrm{p}, 9.01 \%$ and $15.82 \%$ of cells were detected in Sub-G1 phase. These data indicated that the blocking proliferation and

impairing viability of pPeOp were enhanced by IL-6, while weaken with NSC74859 in MC-4 cells. Whereas there have no significant effect in gastric mucosa MC-1 cells (Fig. 4d).

Results of MTS assay and flow cytometry indicated that pPeOp has the effect of blocking proliferation and impaired viability of MC-4 cells, and there was enhanced with IL-6, but weaken with NSC74859 ( $\mathrm{P}<0.05$, Fig. 4a,b,c and d), whereas it has no significant inhibitory effect of normal gastric mucosa MC-1 cells.

\section{Effect of pPeOp on the JAK/STAT3 Signaling Pathway in Gastric Cancer Cells}

To further investigate the underlying mechanism of $\mathrm{pPe} O \mathrm{p}$, the key nodes of the JAK/STAT3 signaling pathway were investigated in MC-4 gastric cancer cells. pPeOp 
decreased the protein expression of JAK1, JAK2, STAT3 and p-STAT3, while SOCS1 and SOCS3 expression were significantly up-regulated (Fig. 5, $\mathrm{P}<0.05$ ).

As an agonist of the JAK/STAT3 signaling pathway, IL-6 activates the JAK/STAT3 signaling pathway and significantly increased the protein expression of JAK1, JAK2, and p-STAT3, and decreased the SOCS1 and SOCS3 protein expression (Fig. 5, $\mathrm{P}<0.05$ ). When IL-6 and pPeOp-treated on gastric cancer cells MC-4, the JAK/STAT3 signaling pathway was significantly inhibited (Fig. 5, $\mathrm{P}<0.05$ ). As an inhibitor of the JAK/STAT3 signaling pathway, NSC74859 inhibits the JAK/STAT3 signaling pathway and significantly decreased the protein expression of JAK1, JAK2, STAT3 and p-STAT3 (Fig. 5, P<0.05). When NSC74859 and pPeOp acted together on MC-4 gastric cancer cells, the JAK/STAT3 signaling pathway also partially decreased or remained inactive (Fig. 5, $\mathrm{P}<0.05$ ). These results suggested that the anti-tumor effect of $\mathrm{pPeO} \mathrm{p}$ is related to its regulation of the JAK/STAT3 signaling pathway.

\section{Establishing STAT3 Knockdown transfected Stable Cells by Lentivirus Transduction}

Lentivirus, which were labeled by an enhanced green fluorescence protein, was used to knockdown the STAT3 expression. After transfected by lentiviruses, more than $80 \%$ of the gastric cancer cells showed bright green fluorescence under the fluorescence microscope on the third day after transduction (Fig. 6). Western blotting and RT-qPCR were used to detect STAT3 mRNA and protein expression levels after lentivirus transduction. As shown in Fig. 6, the mRNA and protein expression of STAT3 were significantly down-regulated by around $70 \%$.

\section{Effect of pPeOp on Xenograft Nude Mice}

Animal experiment was performed in nude mice to detect the anti-tumor effects of pPeOp. pPeOp or PVP was administrated on nude mice by caudal vein injection every 5 days for 4 weeks. Tumor volume and tumor weight were measured before the end of 
the experiments. The average tumor volume of mice in negative control (NC) group being treated with PVP or $\mathrm{pPe} O \mathrm{p}$ were $2441.9 \pm 576.9 \mathrm{~mm}^{3}$ and $1899.1 \pm 465.6 \mathrm{~mm}^{3}$, respectively, (Fig. 7, P<0.05). In knock down (KD) group, after PVP or pPeOp treatments, the tumor volumes were $1342.6 \pm 465.6 \mathrm{~mm}^{3}$ and $718.9 \pm 249.5 \mathrm{~mm}^{3}$, respectively. The average tumor weight of mice in negative control (NC) group being treated with PVP or pPe $O \mathrm{p}$ was $2.46 \pm 0.36 \mathrm{~g}$ and $1.69 \pm 0.12 \mathrm{~g}$, respectively $(\mathrm{P}<0.05$, Fig. 7). In knock down (KD) group, after PVP or pPeOp treatments, the tumor weight was $0.95 \pm 0.25 \mathrm{~g}$ and $0.75 \pm 0.18 \mathrm{~g}$, respectively (Fig. $7, \mathrm{P}<0.05$ ). The tumor inhibition rates in $\mathrm{NC}$ group and $\mathrm{KD}$ group were $31.3 \%$ and $21.0 \%$, respectively. Hence, there is a tendency that $\mathrm{pPe} O \mathrm{p}$ significantly blocked tumorigenesis and knockdown of STAT3 weaken the inhibition of $\mathrm{pPeOp}$.

\section{Discussion}

Despite the treatment advances have been made over the past 20 years, the prognosis of gastric cancer remains to be poor [15-16]. Traditional Chinese medicine has a history of 2000 years with rich experience in treatment of gastric cancer. Previous studies have demonstrated that $O$. lapidescens can effectively inhibit tumor growth, China Food and Drug Administration has approved Leiwan (O. lapidescens) tablet and Leiwan capsule as antitumor auxiliary drugs [17]. pPeOp, extracted from O.lapidescens, was selected to detect in vitro and in vivo anti-tumor effect.

Nowadays, microarrays and high-throughput bioinformatics technologies, are widely used in drug screening, new drug development, and disease diagnosis [18]. Based on the results of our microarray analysis, JAK/STAT3 signaling pathway was selected as the potential target signaling pathway regulated by $\mathrm{pPe} O \mathrm{p}$.

The JAK/STAT3 pathway transmits extracellular information to the nucleus to modulate cell proliferation, apoptosis, differentiation and angiogenesis [19-20]. Numerous studies demonstrated that the JAK/STAT3 signaling pathway is constitutively activated in human gastric cancer, while STAT3 activity is rapid and short-lived in normal cells [21-22]. Cytokines such as interferons, interleukins, and 
growth factors, bind to cell surface receptors and activate JAKs [23-24]. JAKs phosphorylate STAT3, which then form hetero-dimers or homo-dimers and translocate to the nucleus to induce transcription [25-26]. SOCS1 and SOCS3 play a crucial role in preventing the activation of STAT3 through binding and inhibiting JAKs or competing with STATs' phosphorylation binding sites [27-28]. In preclinical models, numerous drugs, such as Tocilizumab and Ruxolitinib, were designed to target aberrant the JAK/STAT3 signaling in gastric carcinoma [29-30]. Inhibition of the JAK/STAT3 signaling pathway, therefore, is an appealing strategy for cancer therapy [31].

In the present study, the gene expression of JAK/STAT3 signaling pathway, including GP130, JAK1, JAK2, STAT3, in MC-4 gastric cancer cell were significantly repressed, whereas SOCS1 and SOCS3 were significantly up-regulated after treatment with various concentrations of $\mathrm{pPe} O \mathrm{p}$ for $24 \mathrm{~h}$. For further study the regulatory role of pPeOp on JAK/STAT3 signal pathway, IL-6 and NSC74859 were used in present study as the agonist and inhibitor of the JAK/STAT3 signaling pathway. IL-6, combining with GP130, activates the JAK/STAT3 signal pathway directly [32]. NSC74859, inhibiting STAT3 phosphorylation and blocking a homology dimer structure of STAT3, was widely used to study the JAK/STAT3 signaling pathway [33-34]. Western blotting results suggested that IL-6 significantly activates JAK/STAT3 signal pathway, but the signal pathway was significantly inhibited when it act with $\mathrm{pPe} O \mathrm{p}$ together.

The anti-tumor effects of $\mathrm{pPeOp}$ have been proved by experiment through blocking proliferation and impairing viability of gastric cancer cells. It is worth noting that the anti-tumor effects of $\mathrm{pPe} O \mathrm{p}$ increased when $\mathrm{pPe} O \mathrm{p}$ was co-treated with IL-6, whereas NSC74859 weaken the anti-tumor effect of pPeOp. PI, a classic fluorescent dye, combines with DNA to emit strong red fluorescence [35]. Detecting the fluorescence intensity of PI binding by flow cytometry, the amount of DNA in the cell is accurately reflected. According to the amount of DNA, the cell cycle is divided into Sub-G1 phase, G1 phase, S phase and G2 phase [36]. It is reported that cell death is related to DNA damage and degradation [37]. Hence, cells in Sub-G1 phase were regarded as 
dead cells. In the present study, the proportion of Sub-G1 in gastric cancer cells was significantly increased after treated with pPeOp. IL-6 significantly increased cells in sub-G1 phase after $\mathrm{pPe} O \mathrm{p}$ treatment, which was consistence with MTS results.

The anticancer effect of $\mathrm{pPeOp}$ was further illustrated in MC-4 xenograft nude mice model. pPeOp significantly inhibited the tumor growth in mice, which was established by MC-4 cells transfected with null-vector. STAT3 knockdown suppressed the tumor growth, furthermore, the tumor inhibition rate decreased on $\mathrm{pPe} O \mathrm{p}$-treated group, which indicated that STAT3 knockdown inhibited the anticancer effect of $\mathrm{pPe} O \mathrm{p}$. Therefore, the in vitro and in vivo data demonstrated that the inhibition on the JAK/STAT3 signaling pathway contributes to the anticancer effect of $\mathrm{pPeOp}$.

\section{Conclusions}

In summary, our data identified that $\mathrm{pPeO} \mathrm{p}$ exhibited promising anticancer effect through inhibiting the JAK/STAT3 signaling pathway. Therefore, $\mathrm{pPeOp}$ may serve as a novel strategy for gastric cancer.

\section{Declarations}

\section{Ethics approval and consent to participate}

The manuscript has not been submitted other journals for publication, in whole or in part, and all the authors listed have approved the manuscript for publication. All animal experiments were carried out in Shanghai GeneChem Corporation experimental center (rodent license SCXK(Shanghai) 2013-0018). The study was approved by the Ethics Committee of Shanghai Linchang Biotechology Corporationand and was in accordance with the Declaration of Helsinki.

\section{Consent for publication}


All authors have seen the contents in the manuscript and agree for its publication. The authors also agree with the order of authorship in the manuscript.

\section{Availability of data and materials}

The datasets used or analyzed during the present study are available from the corresponding author on reasonable request. The gene expression data in our manuscript has been deposited in Gene Expression Omnibus (GEO) (accession number: GSE141914, the direct link: https://www.ncbi.nlm.nih.gov/geo/query/acc.cgi?acc=GSE141914).

\section{Competing interests}

The authors declare that they have no competing interests.

\section{Funding}

The present study was supported by grants from the National Natural Science Foundation Project (81874355) and the Zhejiang Provincial Natural Science Foundation (LY18H280008).

\section{Authors' Contributions}

YC, CL and JL were substantially involved in the conception and design of the study, drafted the manuscript and supervised all experiments. WX and ZL performed the experiments. WX, ZL, MC, YX, ML, CL, JL and YC were involved in the design of the study, the interpretation of the data, and preparation and review of the manuscript. All authors read and approved the final manuscript.

\section{Acknowledgments}


The authors are particularly grateful to Zhejiang Provincial Center for Disease and Prevention Centre for providing us with cells.

\section{References}

1. Ishii T, Kawazoe A and Shitara K. Dawn of precision medicine on gastric cancer. Int J Clin Oncol. 2019;24:779-88.

2. Biagioni A, Skalamera I, Peri S, Schiavone N, Cianchi F, Giommoni E, et al. Update on gastric cancer treatments and gene therapies. Cancer Metastasis Rev. 2019;38:537-48.

3. Xiao S and Zhou L. Gastric cancer: metabolic and metabolomics perspectives (Review). Int J Oncol. 2017;51:5-17.

4. Hironaka S. Anti-angiogenic therapies for gastric cancer. Asia Pac J Clin Oncol. 2019;15:208-17.

5. Ohno N, Miura T, Saito K, Nishijima M, Miyazaki T, Yadomae T. Physicochemical characteristics and antitumor activities of a highly branched fungal (1-3)-beta-D-glucan,OL-2, isolated from Omphalia lapidescens. Chem Pharm Bull (Tokyo). 1992;40:2215-18.

6. Saito K, Nishijima M, Ohno N, Yadomae T, Miyazaki T. Structure and antitumor activity of the less-branched derivatives of an alkali-soluble glucan isolated from Omphalia lapidescens. (Studies on fungal polysaccharide. XXXVIII). Chem Pharm Bull (Tokyo). 1992;40:261-3.

7. Chen YT, Lu QY, Lin MA, Cheng DQ, Ding ZS, Shan LT. A PVP-extract fungal protein of Omphalia lapideacens and its antitumor activity on human gastric tumors and normal cells. Oncol Rep. 2011;26:1519-26.

8. Yang YL, Gong WY, Chen FF, Chen LC, Chen YT. pPeOp from Omphalia lapidescens Schroet induces cell cycle arrest and inhibits the migration of MC-4 gastric tumor cells. Oncol Lett. 2017;14:533-40.

9. Li H, Wang C, Wei Z, Chen W, Guo Z, He Y. Differences in the prognosis of gastric cancer patients of different sexes and races and the molecular mechanisms involved. 
Int J Oncol. 2019;55:1049-68.

10. Livak KJ, Schmittgen TD. Analysis of relative gene expression data using real-time quantitative PCR and the 2(-Delta Delta C(T)) Method. Methods. 2001;25:402-8.

11. Wang W, Liu Y, Liu H, An Y, Wang Q, Liu J. NaK alloy-induced in vivo tumor ablation therapy. Minim Invasive Ther Allied Technol. 2018;27:90-6.

12. Gan BL, He RQ, Zhang Y, Wei DM, Hu XH, Chen G. Downregulation of HOXA3 in lung adenocarcinoma and its relevant molecular mechanism analysed by RT-qPCR, TCGA and in silico analysis. Int J Oncol. 2018;53:1557-79.

13. Adan A, Kiraz Y, Baran Y. Cell Proliferation and Cytotoxicity Assays. Curr Pharm Biotechnol. 2016;17:1213-21.

14. Long HY, Huang QX, Yu YY, Zhang ZB, Yao ZW, Chen HB. Dehydrocostus lactone inhibits in vitro gastrinoma cancer cell growth through apoptosis induction, sub-G1 cell cycle arrest, DNA damage and loss of mitochondrial membrane potential. Arch Med Sci. 2019;15:765-73.

15. Nakanishi K, Kanda M, Kodera Y. Long-lasting discussion: Adverse effects of intraoperative blood loss and allogeneic transfusion on prognosis of patients with gastric cancer. World J Gastroenterol. 2019;25:2743-51.

16. Li H, Wang C, Wei Z, Chen W, Guo Z, He Y. Differences in the prognosis of gastric cancer patients of different sexes and races and the molecular mechanisms involved. Int J Oncol. 2019;55:1049-68.

17. Chen L, Lu Z, Yang Y, Du L, Zhou X, Chen Y. Effects of purified Omphalia lapidescens protein on metastasis, cell cycle, apoptosis and the JAK-STAT signaling pathway in SGC-7901 human gastric cells. Oncol Lett. 2018;15: 4161-70.

18. Zhou Z, Jiang H, Xia J, Zhang J. Comparison of the therapeutic effects of lobaplatin and carboplatin on retinoblastoma in vitro and in vivo. Int J Oncol. 2020;57:697-706.

19. Groner B, von Manstein V. Jak Stat signaling and cancer: opportunities, benefits and side effects of targeted inhibition. Mol Cell Endocrinol. 2017;451:1-14. 
20. Servais FA, Kirchmeyer M, Hamdorf M, Minoungou NWE, Rose-John S, Kreis S. Modulation of the IL-6-Signaling pathway in liver cells by miRNAs targeting gp130, JAK1, and/or STAT3. Mol Ther Nucleic Acids. 2019;16:419-33.

21. Banerjee K, Resat H. Constitutive activation of STAT3 in breast cancer cells: A review. Int J Cancer. 2016;138:2570-78.

22. Cheng Z, Lei Z, Yang P, Si A, Xiang D, Tang X. Exosome-transmitted p120-catenin suppresses hepatocellular carcinoma progression via STAT3 pathways. Mol Carcinog. 2019;58:1389-99.

23. Bharadwaj U, Kasembeli MM, Robinson P, Tweardy DJ. Targeting janus kinases and signal transducer and activator of transcription 3 to treat inflammation, fibrosis, and cancer: rationale, progress, and caution. Pharmacol Rev. 2020;72: 486-526.

24. Hosseini A, Gharibi T, Marofi F, Javadian M, Babaloo Z, Baradaran B. Janus kinase inhibitors: A therapeutic strategy for cancer and autoimmune diseases. $\mathrm{J}$ Cell Physiol. 2020;235:5903-24.

25. Johnson DE, O'Keefe RA, Grandis JR. Targeting the IL-6/JAK/STAT3 signalling axis in cancer. Nat Rev Clin Oncol. 2018;15:234-48.

26. Zhou F, Cheng L, Qiu LX, Wang MY, Li J, Sun MH. Associations of potentially functional variants in IL-6, JAKs and STAT3 with gastric cancer risk in an eastern Chinese population. Oncotarget. 2016;7: 28112-23.

27. Jiang L, Chen T, Xiong L, Xu JH, Gong AY, Dai B. Knockdown of m6A methyltransferase METTL3 in gastric cancer cells results in suppression of cell proliferation. Oncol Lett. 2020;20: 2191-8.

28. Linossi EM, Calleja DJ, Nicholson SE. Understanding SOCS protein specificity. Growth Factors. 2018;36:104-17.

29. Sheppard M, Laskou F, Stapleton PP, Hadavi S, Dasgupta B. Tocilizumab (Actemra). Hum Vaccin Immunother. 2017;13:1972-88.

30. Greenfield G, McPherson S, Mills K, McMullin MF. The ruxolitinib effect: understanding how molecular pathogenesis and epigenetic dysregulation impact therapeutic efficacy in myeloproliferative neoplasms. J Transl Med. 2018;16: 
360-76.

31. Bharadwaj U, Kasembeli MM, Robinson P, Tweardy DJ. Targeting Janus Kinases and Signal Transducer and Activator of Transcription 3 to Treat Inflammation, Fibrosis, and Cancer: Rationale, Progress, and Caution. Pharmacol Rev. 2020;72:486-526.

32. Kang S, Tanaka T, Narazaki M, Kishimoto T. Targeting interleukin-6 signaling in clinic. Immunity. 2019;50:1007-23.

33. Wang Z, Li J, Xiao W, Long J, Zhang H. The STAT3 inhibitor S3I-201 suppresses fibrogenesis and angiogenesis in liver fibrosis. Lab Invest. 2018;98:1600-13.

34. Nishimura K, Goto K, Nakagawa H. Effect of erythropoietin production induced by hypoxia on autophagy in HepG2 cells. Biochem Biophys Res Commun. 2018;495:1317-21.

35. Bode KJ, Mueller S, Schweinlin M, Metzger M, Brunner T. A fast and simple fluorometric method to detect cell death in 3D intestinal organoids. Biotechniques. 2019;67:23-8.

36. Meng Q, Tang B, Qiu B. Growth inhibition of Saos-2 osteosarcoma cells by lactucopicrin is mediated via inhibition of cell migration and invasion, sub-G1 cell cycle disruption, apoptosis induction and Raf signalling pathway. J BUON. 2019;24: 2136-40.

37. Chang YM, Shih YL, Chen CP, Liu KL, Lee MH, Lee MZ. Ouabain induces apoptotic cell death in human prostate DU 145 cancer cells through DNA damage and TRAIL pathways. Environ Toxicol. 2019;34:1329-39.

\section{Figures}


A Molecular function

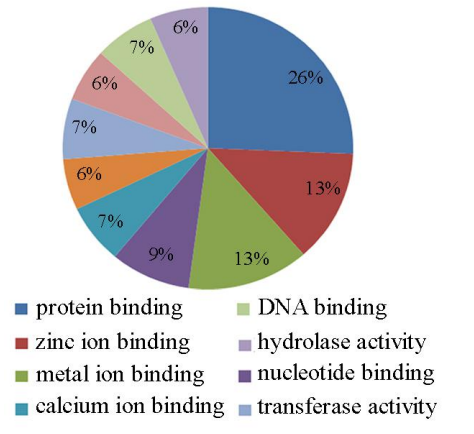

B

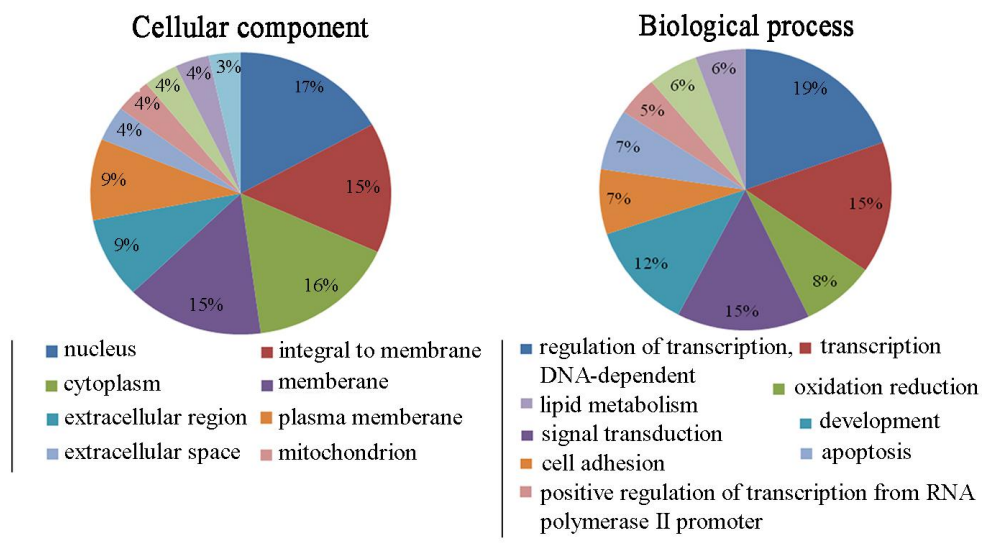

KEGG Signal Pathway Enrichment

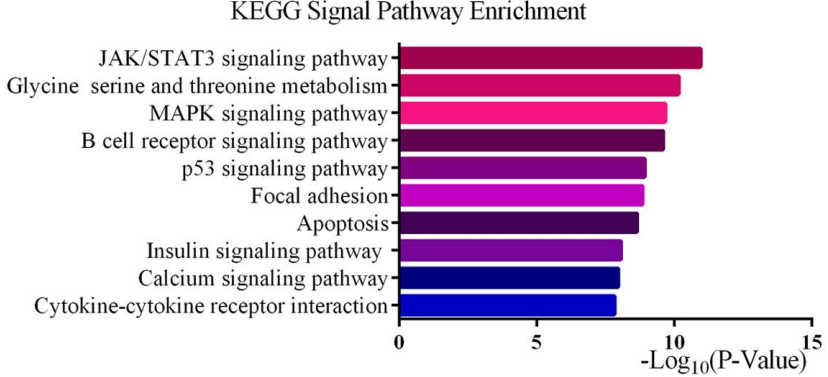

Fig. 1 Genomic analysis of DEGs after being treated with pPeOp. a Gene ontology results of different expressed genes (DEGs). Microarray was used to assay the DEGs followed being treated with PVP $(90 \mu \mathrm{g} / \mathrm{ml})$ or pPeOp $(90 \mu \mathrm{g} / \mathrm{ml})$ for $24 \mathrm{~h}$ in MC-4 cells. b KEGG signaling pathway enrichment results of DEGs. 

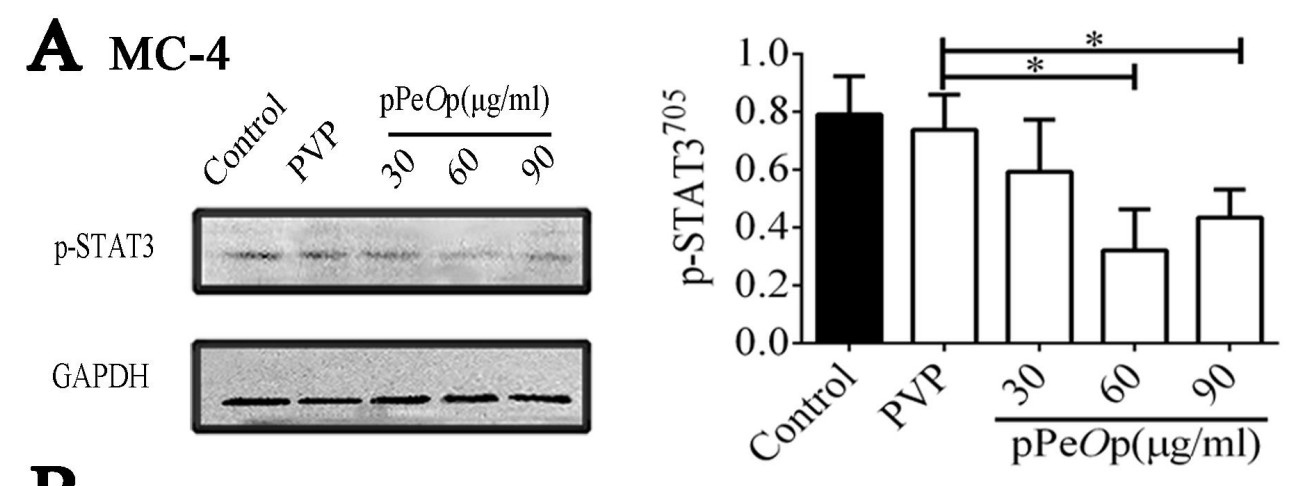

B
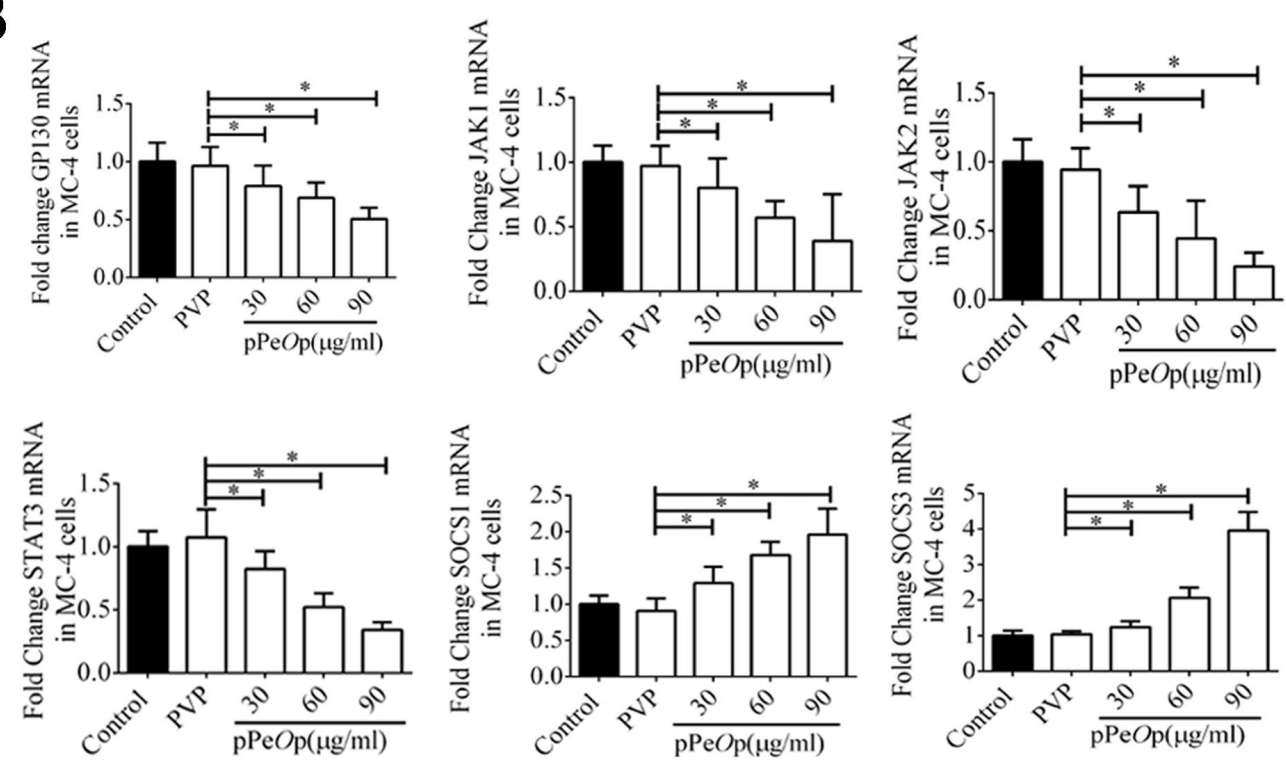

Fig. 2 Genomic analysis of protein and mRNA levels after being treated with pPe $O p$. a PVP $(90 \mu \mathrm{g} / \mathrm{ml})$ and $\mathrm{pPe} O \mathrm{p}(30,60,90 \mu \mathrm{g} / \mathrm{ml})$ were used to treat $\mathrm{MC}-4$ gastric cancer cells for $24 \mathrm{~h}$, respectively. p-STAT3 protein expression, then, was detected by western blotting. b The mRNA expression of JAK1, JAK2, GP130, SOCS1, SOCS3 and STAT3 were detected by RT-qPCR in MC-4 gastric cancer cells after being treated with PVP $(90 \mu \mathrm{g} / \mathrm{ml})$ and $\mathrm{pPe} O \mathrm{p}(30,60,90 \mu \mathrm{g} / \mathrm{ml})$ for $24 \mathrm{~h}$. Results are showed express as mean $\pm \mathrm{SD}$ from three separate experiments. ${ }^{*} \mathrm{P}<0.05$ vs. PVP treatment group. Full-length blots are presented in Supplementary Figure 2. 

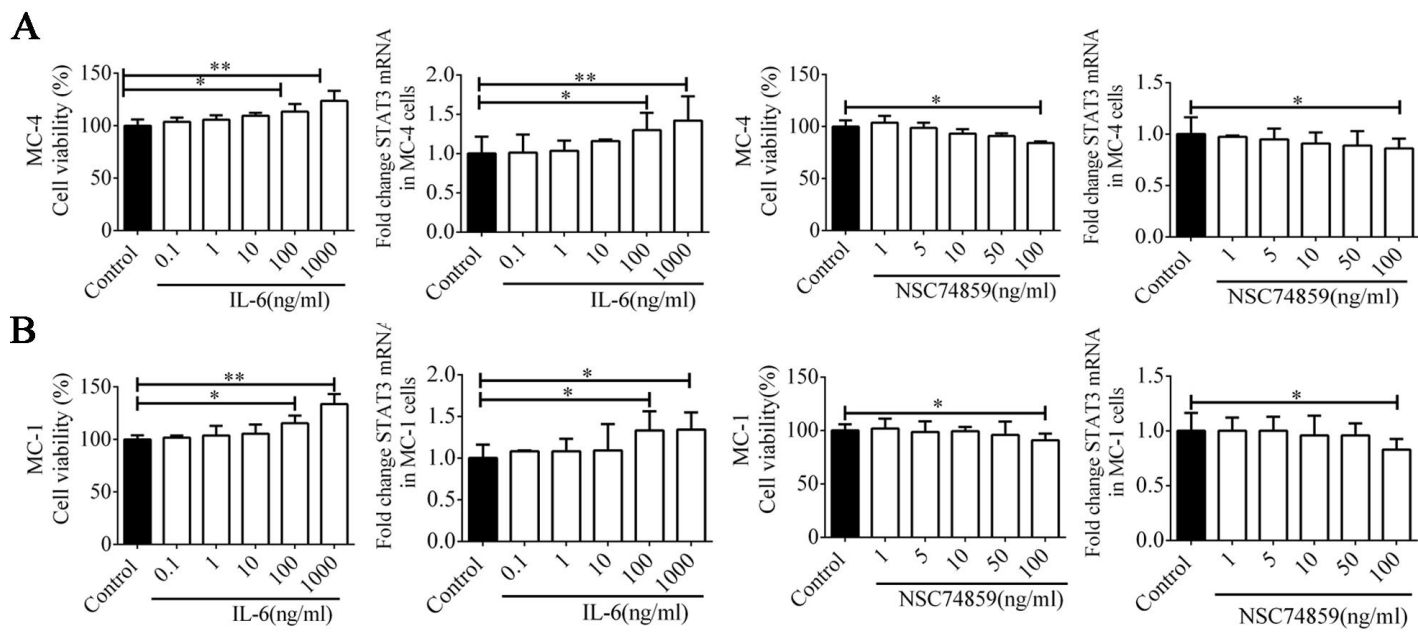

Fig. 3 Optimum concentration selection of agonist and inhibitor. a Cell viability and STAT3 mRNA expression level after being treated with different dose of IL-6 $(0.1,1,10,100,1000 \mathrm{ng} / \mathrm{ml})$ or $\operatorname{NSC74859}(1,5,10,50,100 \mathrm{ng} / \mathrm{ml})$ in MC-4 gastric cancer cells for $24 \mathrm{~h}$. b Cell viability and STAT3 mRNA expression level after being treated with different dose of IL-6 $(0.1,1,10,100,1000 \mathrm{ng} / \mathrm{ml})$ or NSC74859 $(1,5,10,50,100 \mathrm{ng} / \mathrm{ml})$ in MC-1 cells for $24 \mathrm{~h}$. Results are expressed as mean $\pm \mathrm{SD}$ from three separate experiments. $* \mathrm{P}<0.05$ and $* * \mathrm{P}<0.01$ vs. control group. 
A
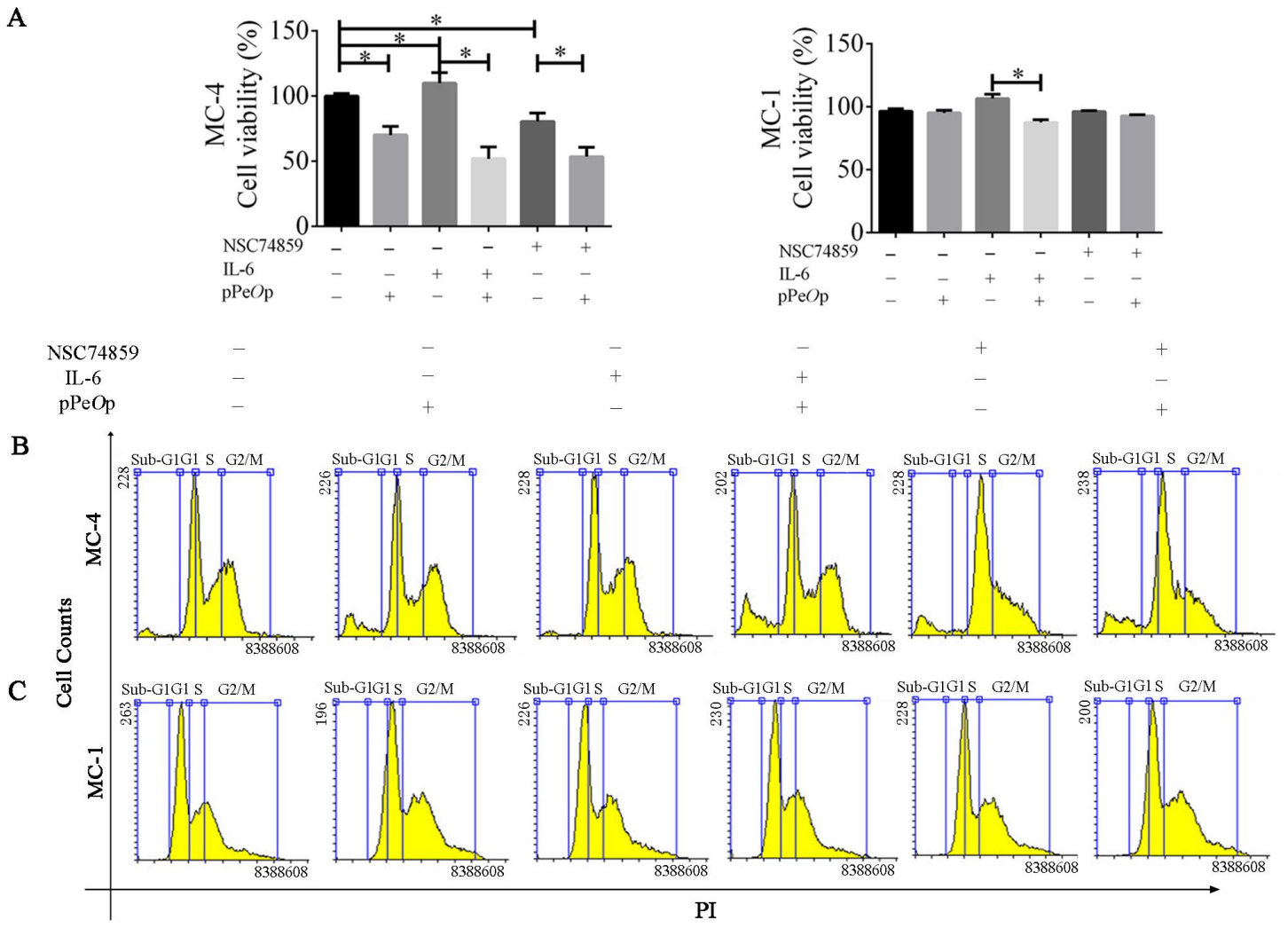

D
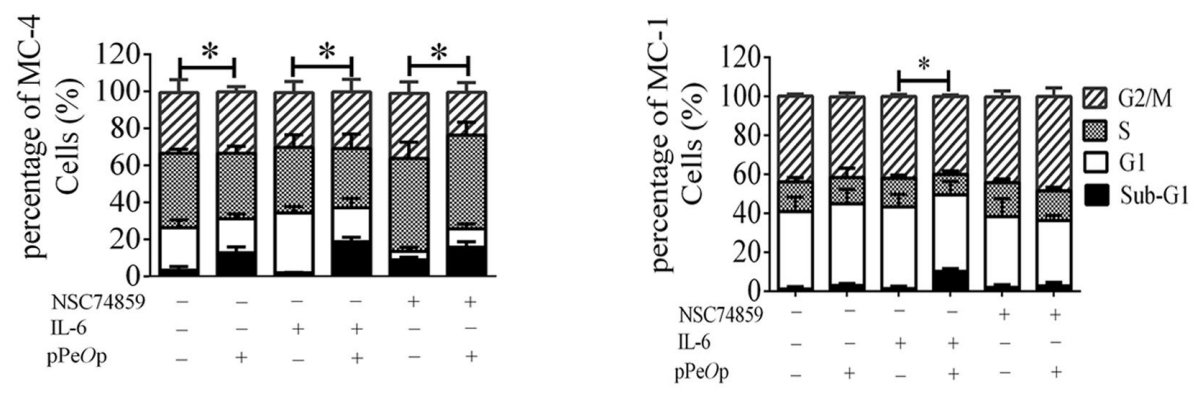

Fig. 4 Effects of $\mathrm{pPeOp}$ on viability and DNA contents of different phase cells in human gastric cancer cells and human gastric cells. a Cell viability tested by MTS assay. b \& c DNA contents of different phase cells analyzed by flow cytometry. b MC-4 and c MC-1 cells were treated with pPeOp $(60 \mu \mathrm{g} / \mathrm{ml})$ for $24 \mathrm{~h}$ in the absence or presence of NSC74859 $(100 \mathrm{ng} / \mathrm{ml})$ or IL-6 $(100 \mathrm{ng} / \mathrm{ml})$. d Statistical analysis results of flow cytometry. Results are expressed as mean \pm SD from three separate experiments. ${ }^{*} \mathrm{P}<0.05$ vs. control group or as indicated. 

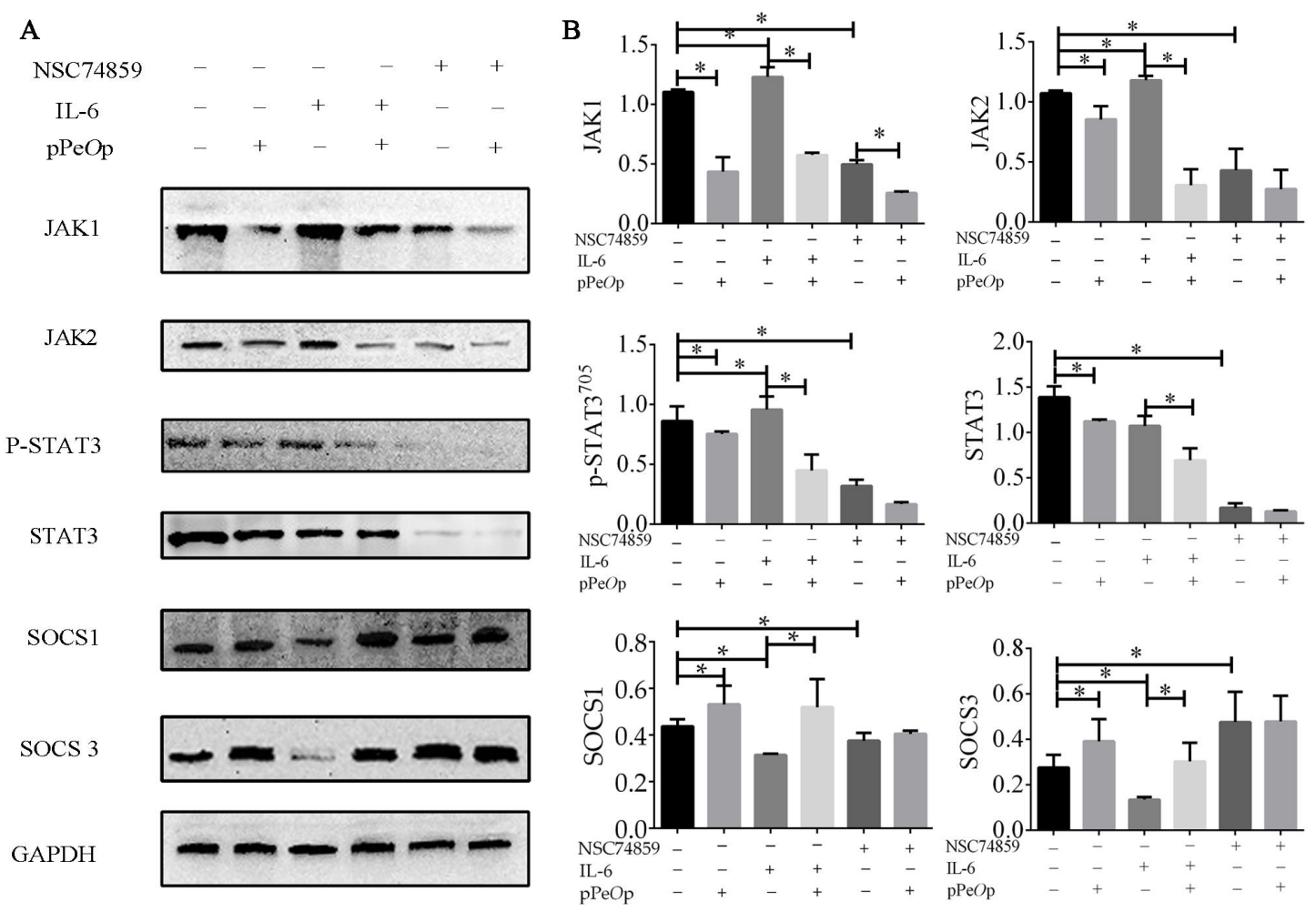

Fig. 5 Effect of pPeOp on the JAK/STAT3 signaling pathway in gastric cancer cells. MC-4 gastric cancer cells were treated with $\mathrm{pPe} O \mathrm{p}(60 \mu \mathrm{g} / \mathrm{ml})$ in the absence or presence of NSC74859 (100 ng/ml) or IL-6 (100 ng/ml) for $24 \mathrm{~h}$. a Western blotting was used for detecting the protein expression levels of JAK1, JAK2, STAT3, p-STAT3, SOCS1 and SOCS3. b Results are showed express as mean \pm SD from three separate experiments. ${ }^{*} \mathrm{P}<0.05$ vs. control group or as indicated. Full-length blots are presented in Supplementary Figure 5. 


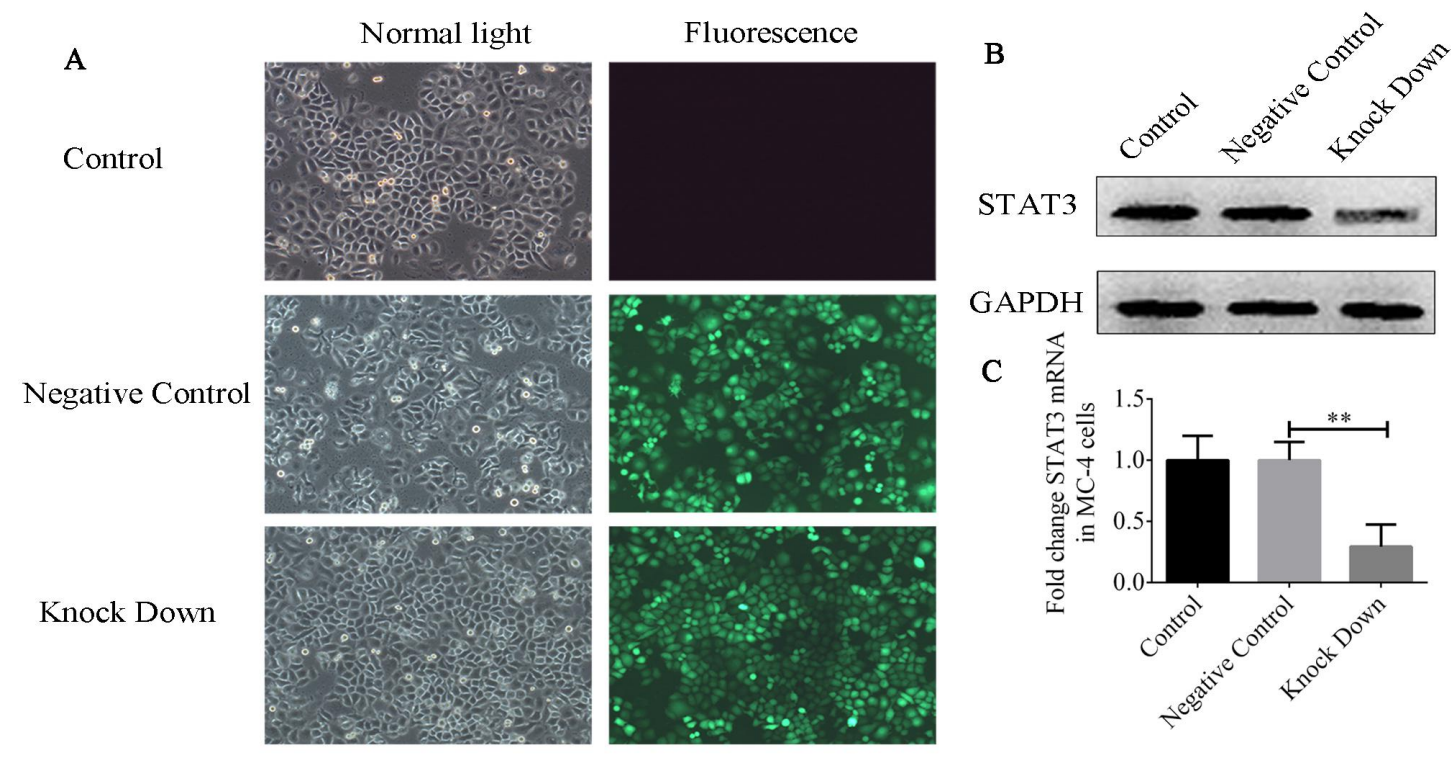

Fig. 6 MC-4 gastric cancer cells were transfected by lentivirus. a Cell morphology under normal light and fluorescence (20x). b STAT3 protein expression was detected by western blotting. c STAT3 gene expression in MC-4 cells was detected by RT-qPCR after transfected by lentivirus. Results are showed express as mean \pm SD from three separate experiments. ${ }^{* *} \mathrm{P}<0.01$ vs. negative control group. Full-length blots are presented in Supplementary Figure 6. 


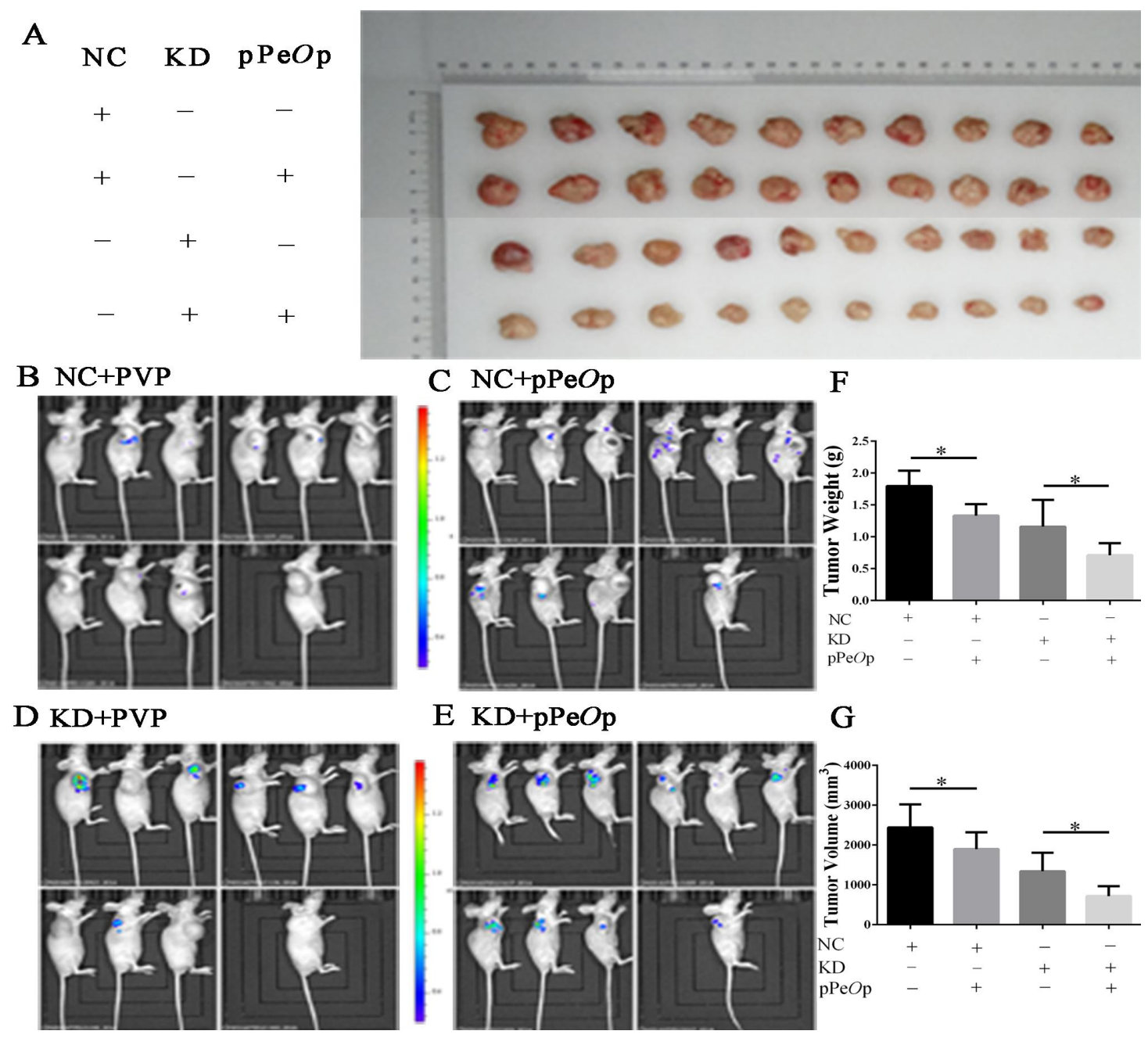

Fig. 7 Anticancer effects of $\mathrm{pPeOp}$ in xenograft nude mice. a PVP $(10 \mathrm{mg} / \mathrm{kg})$ or $\mathrm{pPe} O \mathrm{p}(10 \mathrm{mg} / \mathrm{kg})$ were treated via tail vein injection every 5 days. Tumors were excised out of the mice at day 25. b \& $\mathbf{c}$ The living images of nude mice in negative control group, which being treated with PVP $(10 \mathrm{mg} / \mathrm{kg}, 10$ nude mice in Fig. 7B) and pPeOp (10 mg/kg, 10 nude mice in Fig. 7C), respectively. d \& e The living images of nude mice in STAT3 knock down group, which being treated with PVP (10mg/kg, 10 nude mice in Fig. 7D) and pPeOp (10 mg/kg, 10 nude mice in Fig. 7E), respectively. $\mathbf{f}$ Tumor weight of different groups of nude mice. $\mathbf{g}$ Tumor volume of different groups of nude mice. Results are showed express as mean $\pm \mathrm{SD}, \mathrm{n}=10$. ${ }^{*} \mathrm{P}<0.05$ vs. NC group or as indicated. 
A Molecular function

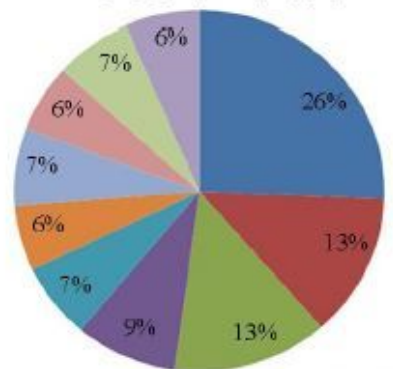

w protein binding

a zinc ion binding

- $\mathrm{DNA}$ binding

metal ion binding

nydrolase activity

nucleotide binding

a calcium ion binding $=$ transferase activity
Cellular component

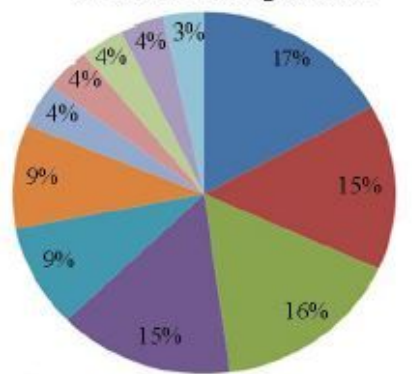

nucleus

= cytoplasm

n integral to membrane

n memberane

a extracellular region = plasma memberane

m extracellular space $=$ mitochondrion
Biological process

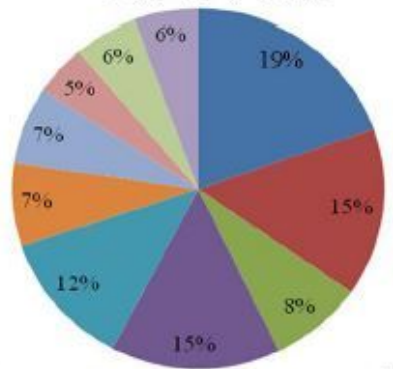

- regulation of transcription, = transcription

DNA-dependent

- lipid metabolism

- signal transduction

= cell adhesion

= oxidation reduction

- development

apoptosis

n positive regulation of transcription from RNA polymerase II promoter

B

KEGG Signal Pathway Enrichment

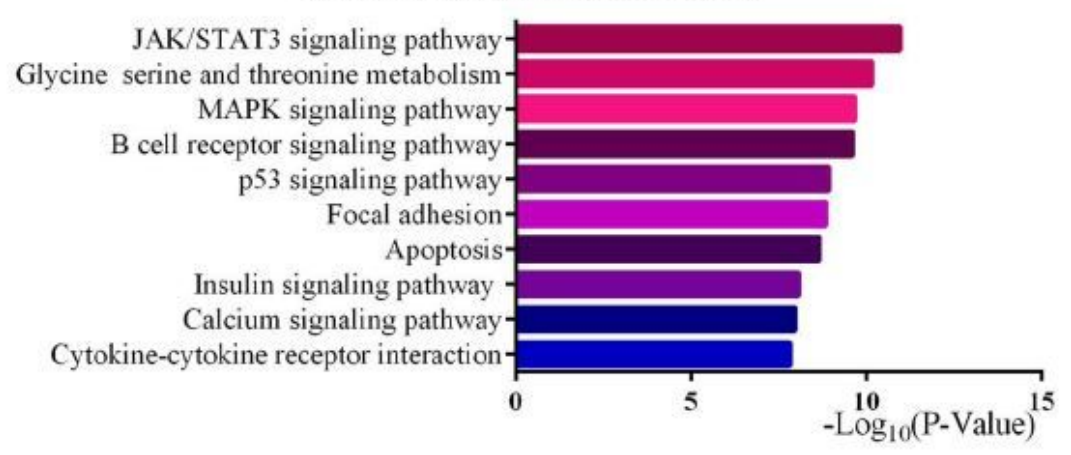

\section{Figure 1}

Genomic analysis of DEGs after being treated with pPeOp. a Gene ontology results of different expressed genes (DEGs). Microarray was used to assay the DEGs followed being treated with PVP $(90 \mu \mathrm{g} / \mathrm{ml})$ or pPeOp $(90 \mu \mathrm{g} / \mathrm{ml})$ for $24 \mathrm{~h}$ in MC-4 cells. b KEGG signaling pathway enrichment results of DEGs. 
A Molecular function

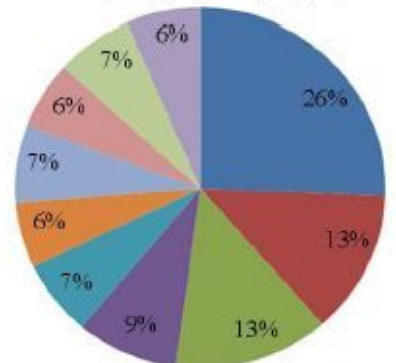

a protein binding

ENA binding

a zinc ion binding = hydrolase activity

= metal ion binding $=$ nucleotide binding

w calcium ion binding $=$ transferase activity
Cellular component

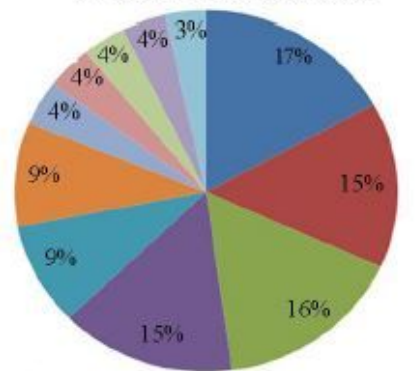

nucleus

n cytoplasm

- integral to membrane nemberane

= extracellular region = plasma memberane

m extracellular space $=$ mitochondrion
Biological process

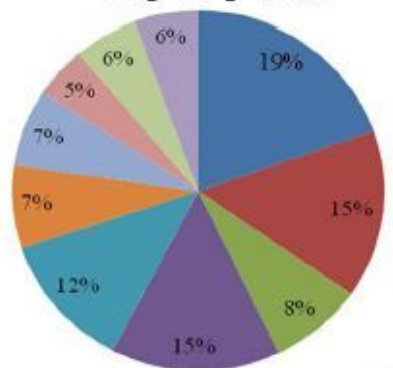

- regulation of transcription, = transcription DNA-dependent

- lipid metabolism

- signal transduction

- cell adhesion

=xidation reduction = development

= apoptosis

= positive regulation of transcription from RNA polymerase II promoter

B

KEGG Signal Pathway Enrichment

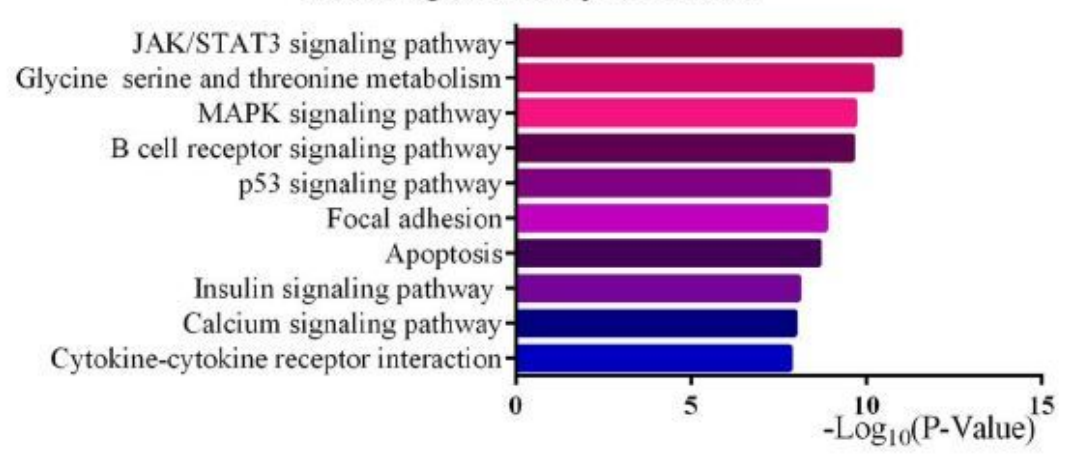

\section{Figure 1}

Genomic analysis of DEGs after being treated with pPeOp. a Gene ontology results of different expressed genes (DEGs). Microarray was used to assay the DEGs followed being treated with PVP $(90 \mu \mathrm{g} / \mathrm{ml})$ or pPeOp $(90 \mu \mathrm{g} / \mathrm{ml})$ for $24 \mathrm{~h}$ in MC-4 cells. b KEGG signaling pathway enrichment results of DEGs. 
A Molecular function

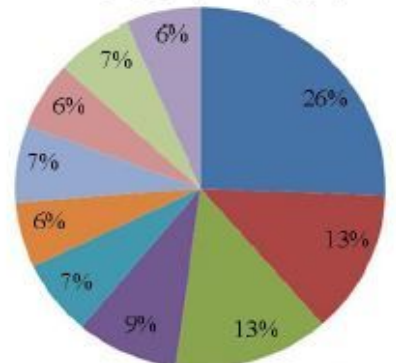

a protein binding

ENA binding

a zinc ion binding = hydrolase activity

= metal ion binding $=$ nucleotide binding

w calcium ion binding $=$ transferase activity
Cellular component

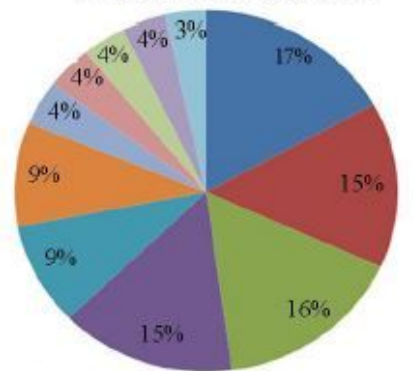

nucleus

n cytoplasm

- integral to membrane nemberane

= extracellular region = plasma memberane

m extracellular space $=$ mitochondrion
Biological process

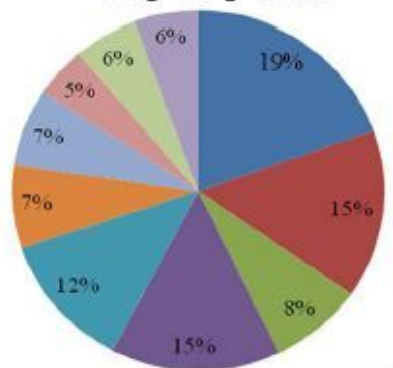

- regulation of transcription, = transcription DNA-dependent

- lipid metabolism

- signal transduction

- cell adhesion

=xidation reduction = development

= apoptosis

= positive regulation of transcription from RNA polymerase II promoter

B

KEGG Signal Pathway Enrichment

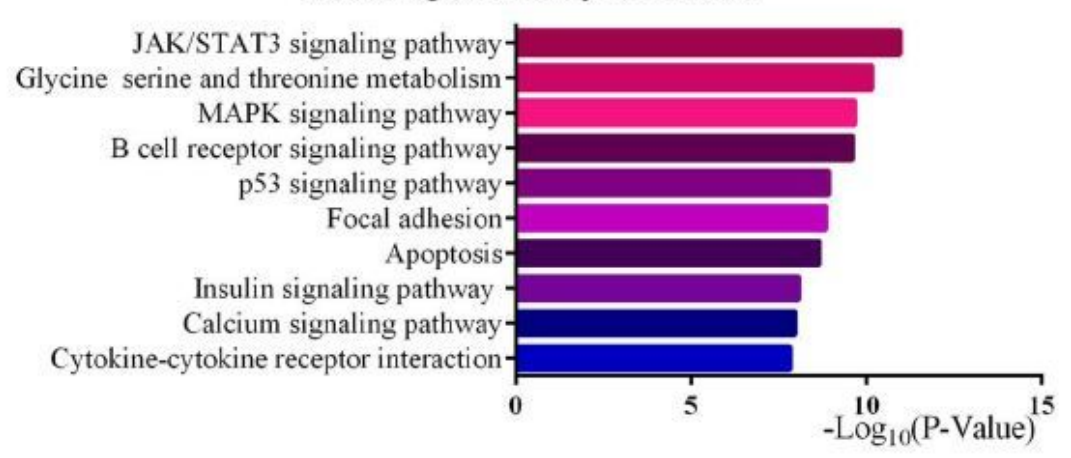

\section{Figure 1}

Genomic analysis of DEGs after being treated with pPeOp. a Gene ontology results of different expressed genes (DEGs). Microarray was used to assay the DEGs followed being treated with PVP $(90 \mu \mathrm{g} / \mathrm{ml})$ or pPeOp $(90 \mu \mathrm{g} / \mathrm{ml})$ for $24 \mathrm{~h}$ in MC-4 cells. b KEGG signaling pathway enrichment results of DEGs. 
A MC-4

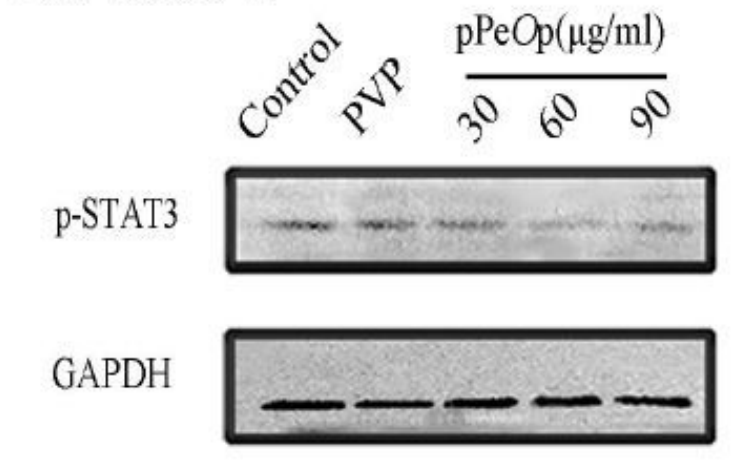

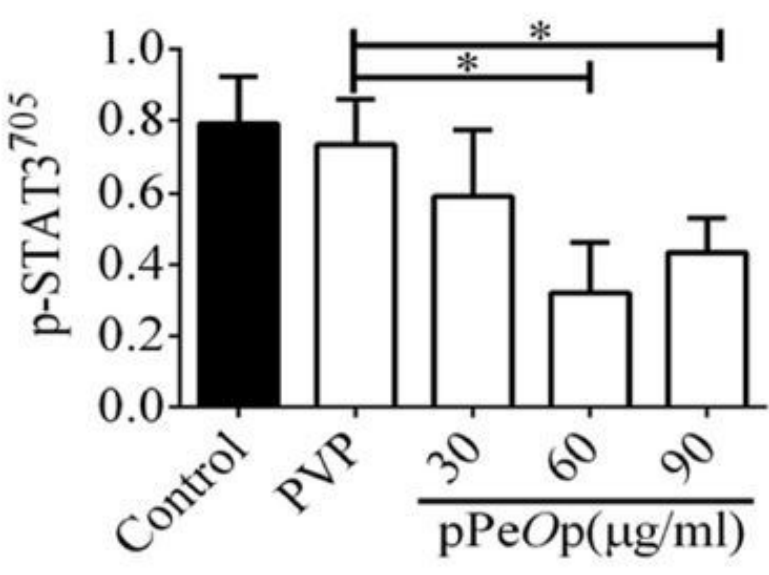

B
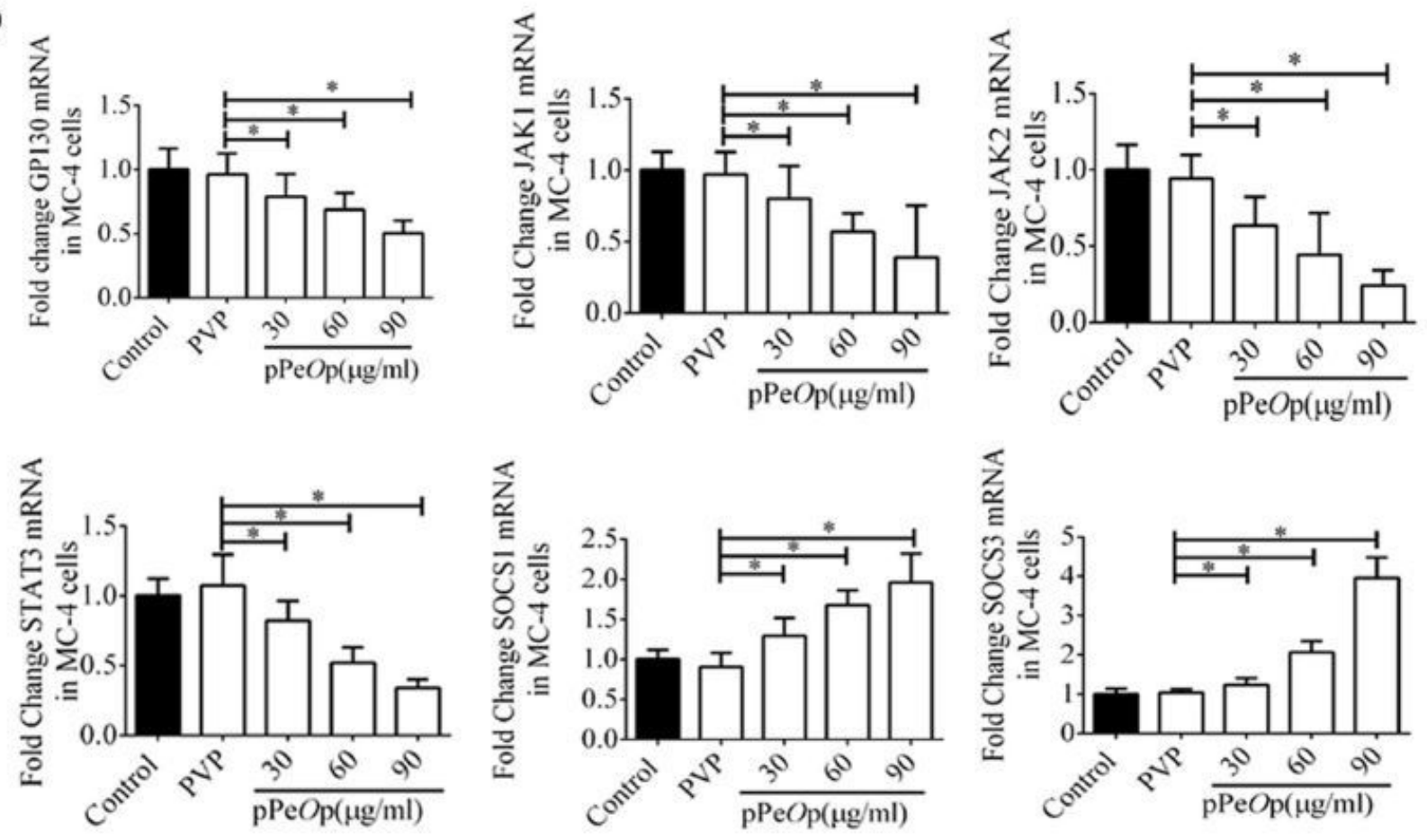

Figure 2

Genomic analysis of protein and mRNA levels after being treated with pPeOp. a PVP $(90 \mu \mathrm{g} / \mathrm{ml})$ and pPeOp $(30,60,90 \mu \mathrm{g} / \mathrm{ml})$ were used to treat MC-4 gastric cancer cells for $24 \mathrm{~h}$, respectively. $\mathrm{p}$-STAT3 protein expression, then, was detected by western blotting. $b$ The mRNA expression of JAK1, JAK2, GP130, SOCS1, SOCS3 and STAT3 were detected by RT-qPCR in MC-4 gastric cancer cells after being treated with PVP $(90 \mu \mathrm{g} / \mathrm{ml})$ and pPeOp $(30,60,90 \mu \mathrm{g} / \mathrm{ml})$ for $24 \mathrm{~h}$. Results are showed express as mean $\pm \mathrm{SD}$ from three separate experiments. ${ }^{*} \mathrm{P}<0.05$ vs. PVP treatment group. Full-length blots are presented in Supplementary Figure 2. 
A MC-4

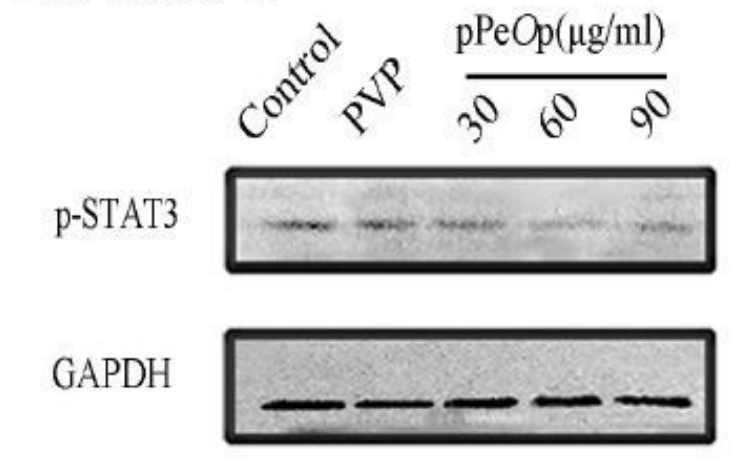

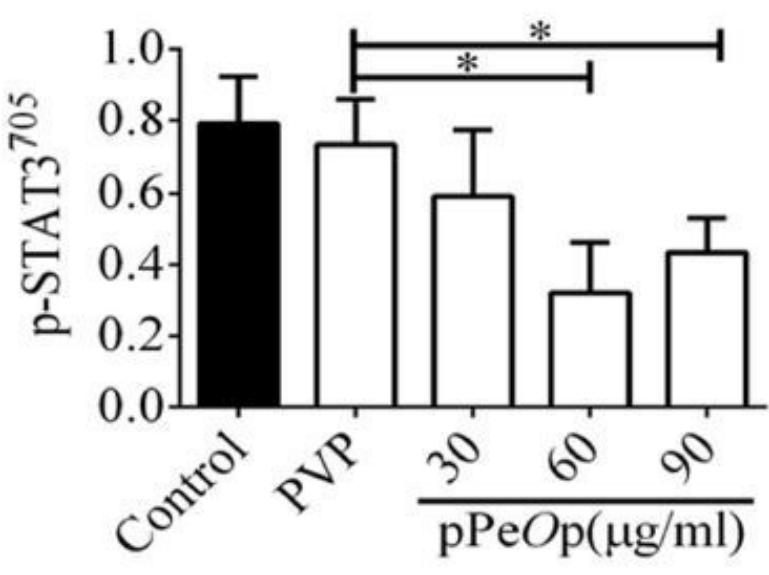

B
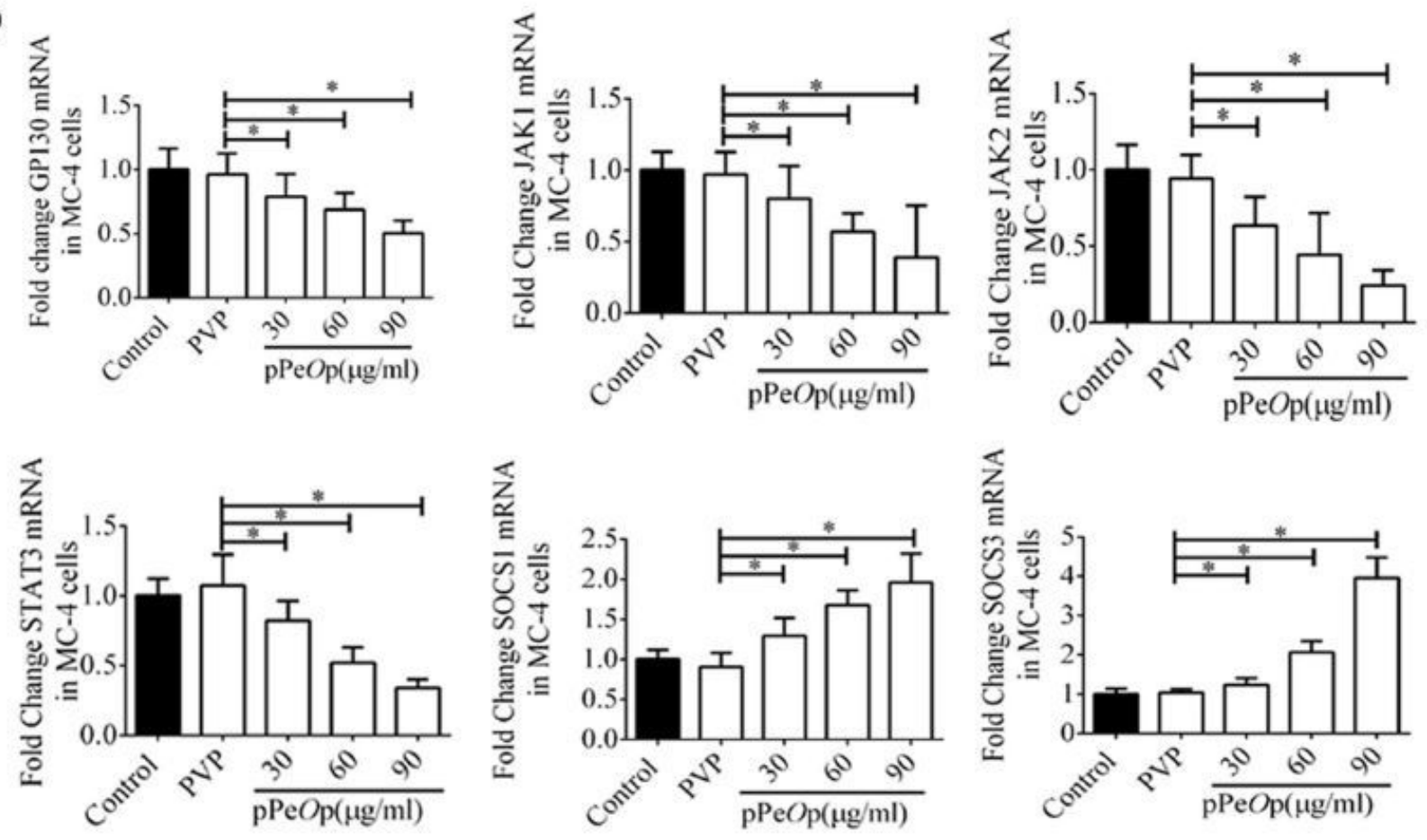

Figure 2

Genomic analysis of protein and mRNA levels after being treated with pPeOp. a PVP $(90 \mu \mathrm{g} / \mathrm{ml})$ and pPeOp $(30,60,90 \mu \mathrm{g} / \mathrm{ml})$ were used to treat MC-4 gastric cancer cells for $24 \mathrm{~h}$, respectively. $\mathrm{p}$-STAT3 protein expression, then, was detected by western blotting. $b$ The mRNA expression of JAK1, JAK2, GP130, SOCS1, SOCS3 and STAT3 were detected by RT-qPCR in MC-4 gastric cancer cells after being treated with PVP $(90 \mu \mathrm{g} / \mathrm{ml})$ and pPeOp $(30,60,90 \mu \mathrm{g} / \mathrm{ml})$ for $24 \mathrm{~h}$. Results are showed express as mean $\pm \mathrm{SD}$ from three separate experiments. ${ }^{*} \mathrm{P}<0.05$ vs. PVP treatment group. Full-length blots are presented in Supplementary Figure 2. 


\section{A MC-4}
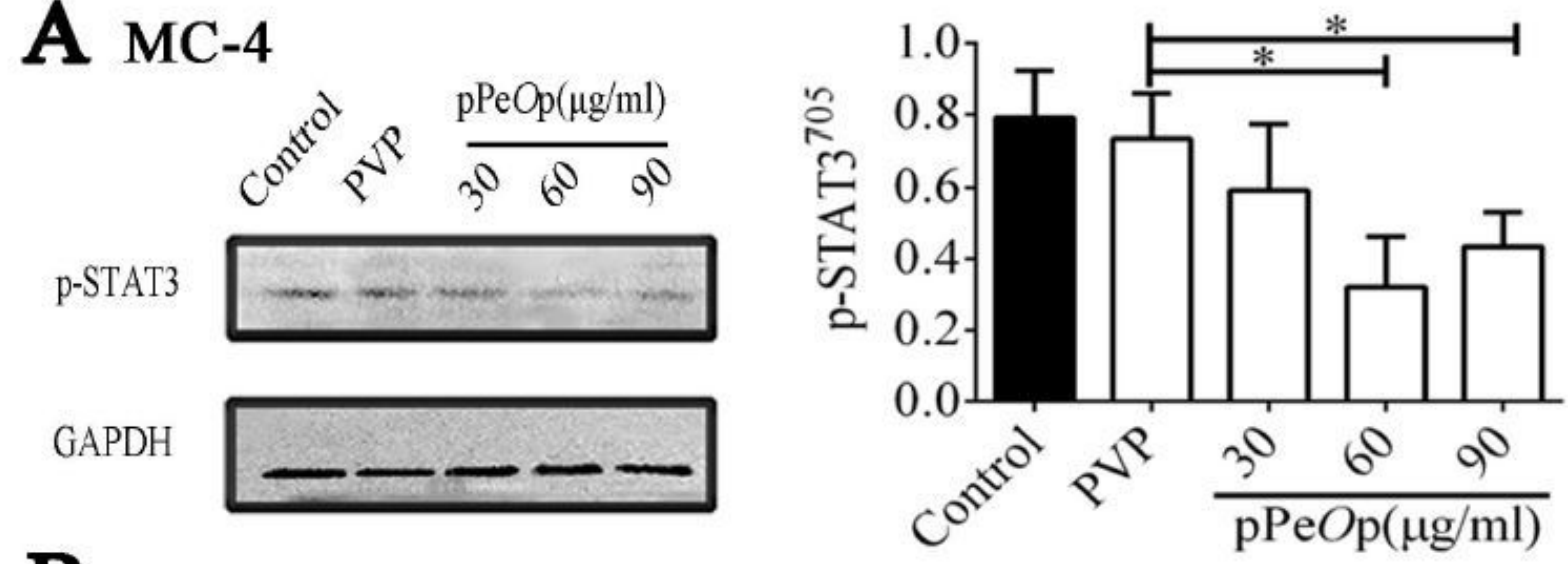

B
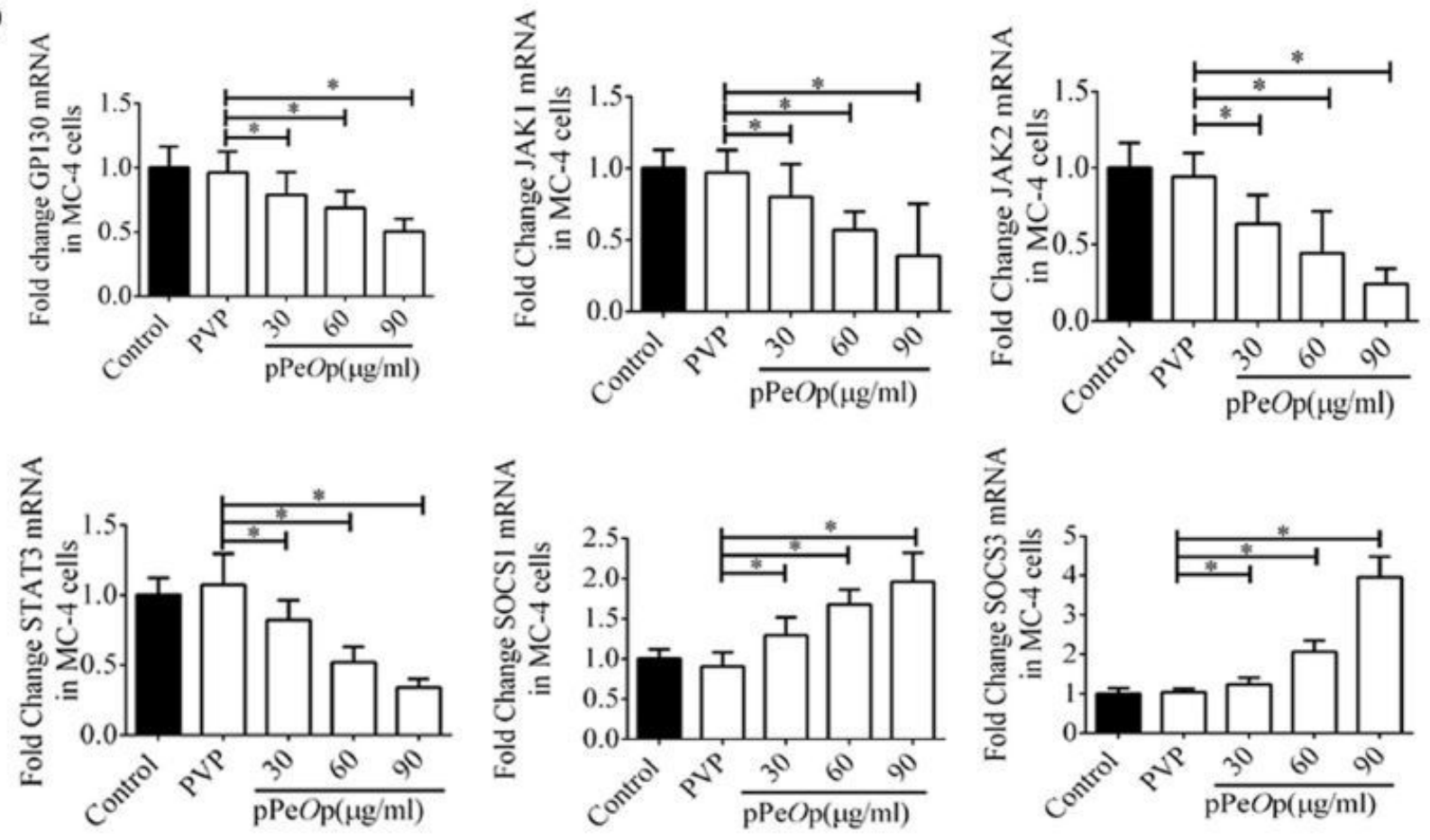

Figure 2

Genomic analysis of protein and mRNA levels after being treated with pPeOp. a PVP $(90 \mu \mathrm{g} / \mathrm{ml})$ and pPeOp $(30,60,90 \mu \mathrm{g} / \mathrm{ml})$ were used to treat MC-4 gastric cancer cells for $24 \mathrm{~h}$, respectively. $\mathrm{p}$-STAT3 protein expression, then, was detected by western blotting. $b$ The mRNA expression of JAK1, JAK2, GP130, SOCS1, SOCS3 and STAT3 were detected by RT-qPCR in MC-4 gastric cancer cells after being treated with PVP $(90 \mu \mathrm{g} / \mathrm{ml})$ and pPeOp $(30,60,90 \mu \mathrm{g} / \mathrm{ml})$ for $24 \mathrm{~h}$. Results are showed express as mean $\pm \mathrm{SD}$ from three separate experiments. ${ }^{*} \mathrm{P}<0.05$ vs. PVP treatment group. Full-length blots are presented in Supplementary Figure 2. 

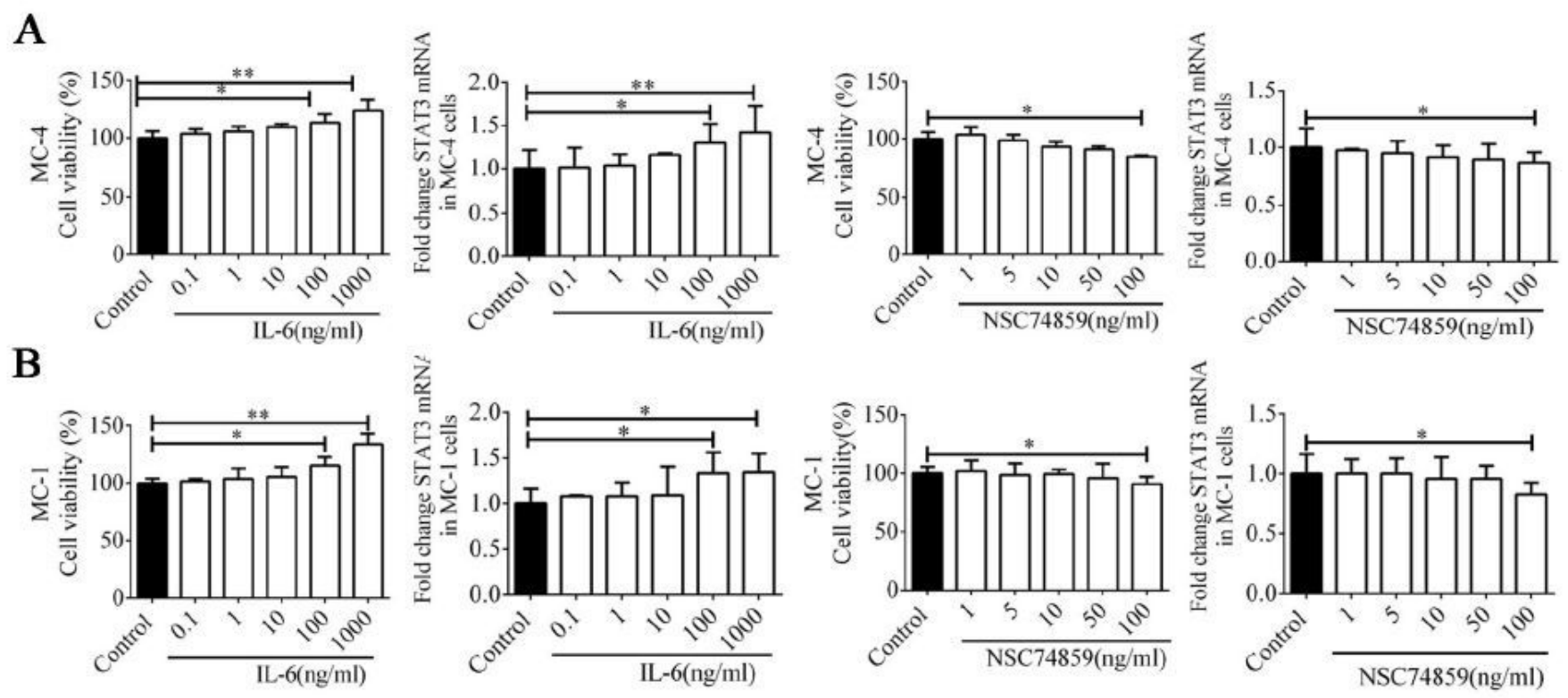

Figure 3

Optimum concentration selection of agonist and inhibitor. a Cell viability and STAT3 mRNA expression level after being treated with different dose of IL-6 $(0.1,1,10,100,1000 \mathrm{ng} / \mathrm{ml})$ or NSC74859 $(1,5,10,50,100$ $\mathrm{ng} / \mathrm{ml}$ ) in MC-4 gastric cancer cells for $24 \mathrm{~h}$. b Cell viability and STAT3 mRNA expression level after being treated with different dose of IL-6 $(0.1,1,10,100,1000 \mathrm{ng} / \mathrm{ml})$ or NSC74859 $(1,5,10,50,100 \mathrm{ng} / \mathrm{ml})$ in MC-1 cells for $24 \mathrm{~h}$. Results are expressed as mean \pm SD from three separate experiments. ${ }^{*} \mathrm{P}<0.05$ and $* \star P<$ 0.01 vs. control group.
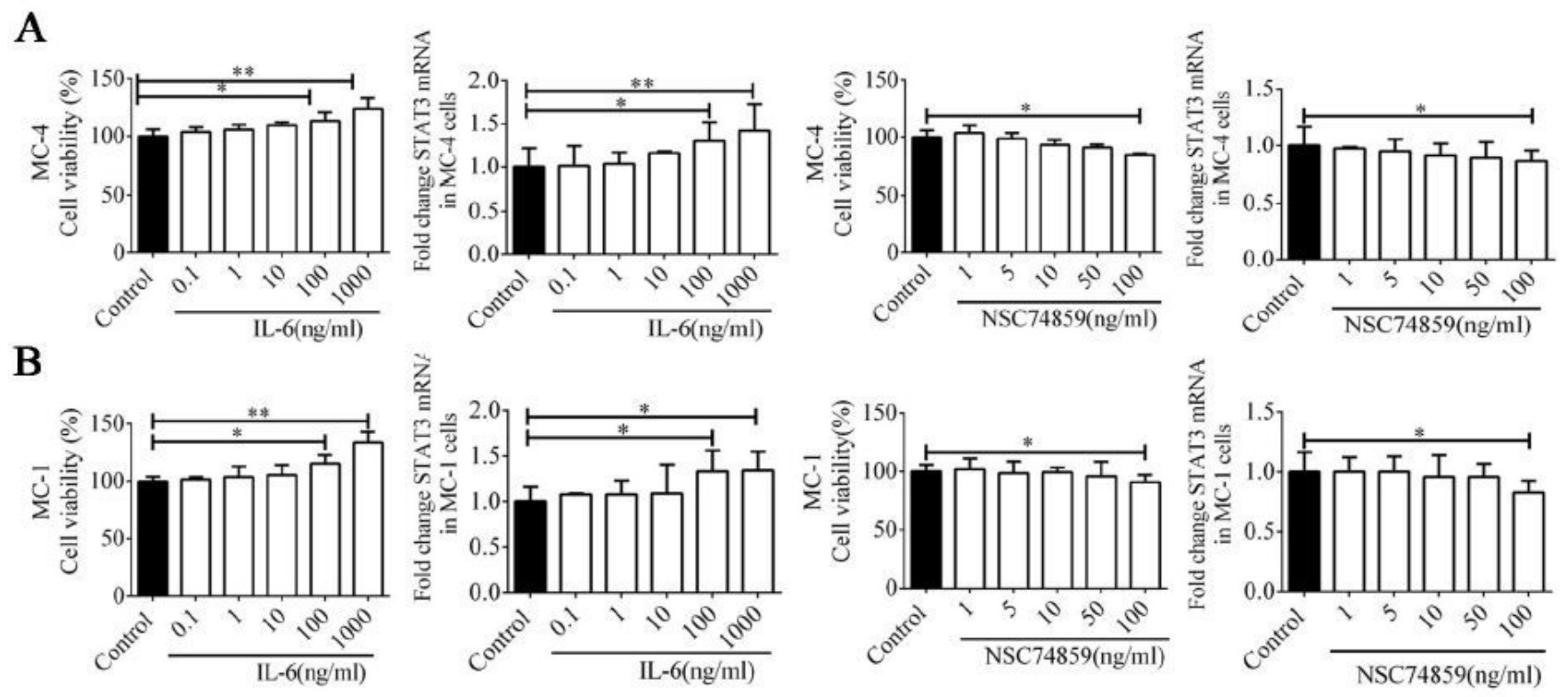


\section{Figure 3}

Optimum concentration selection of agonist and inhibitor. a Cell viability and STAT3 mRNA expression level after being treated with different dose of IL-6 $(0.1,1,10,100,1000 \mathrm{ng} / \mathrm{ml})$ or NSC74859 $(1,5,10,50,100$ $\mathrm{ng} / \mathrm{ml}$ ) in MC-4 gastric cancer cells for $24 \mathrm{~h}$. b Cell viability and STAT3 mRNA expression level after being treated with different dose of IL-6 $(0.1,1,10,100,1000 \mathrm{ng} / \mathrm{ml})$ or NSC74859 $(1,5,10,50,100 \mathrm{ng} / \mathrm{ml})$ in MC-1 cells for $24 \mathrm{~h}$. Results are expressed as mean \pm SD from three separate experiments. ${ }^{*}<<0.05$ and $* \star P<$ 0.01 vs. control group.
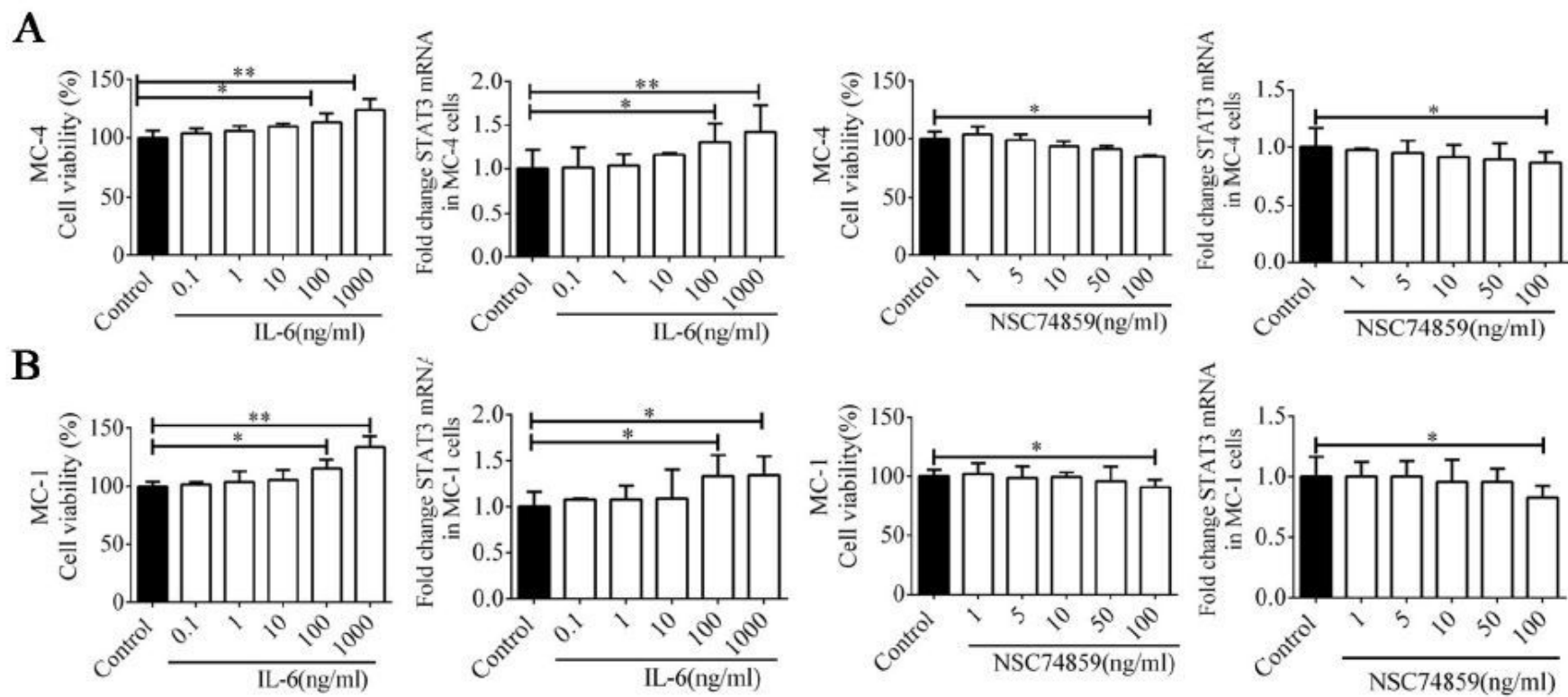

\section{Figure 3}

Optimum concentration selection of agonist and inhibitor. a Cell viability and STAT3 mRNA expression level after being treated with different dose of IL-6 $(0.1,1,10,100,1000 \mathrm{ng} / \mathrm{ml})$ or NSC74859 $(1,5,10,50,100$ $\mathrm{ng} / \mathrm{ml}$ ) in MC-4 gastric cancer cells for $24 \mathrm{~h}$. b Cell viability and STAT3 mRNA expression level after being treated with different dose of IL-6 $(0.1,1,10,100,1000 \mathrm{ng} / \mathrm{ml})$ or NSC74859 $(1,5,10,50,100 \mathrm{ng} / \mathrm{ml})$ in MC-1 cells for $24 \mathrm{~h}$. Results are expressed as mean \pm SD from three separate experiments. ${ }^{*} \mathrm{P}<0.05$ and $* \star P<$ 0.01 vs. control group. 
A
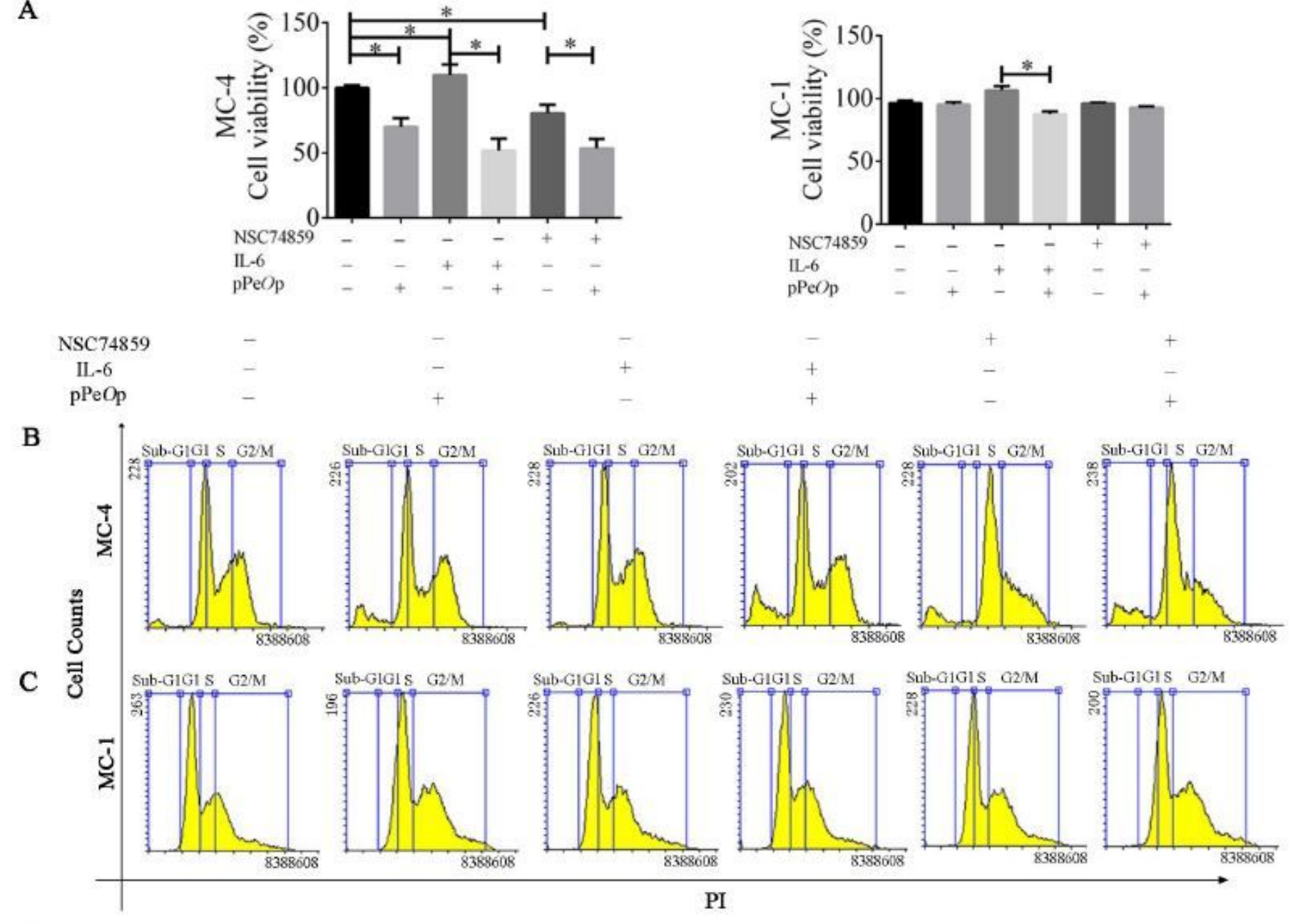

D
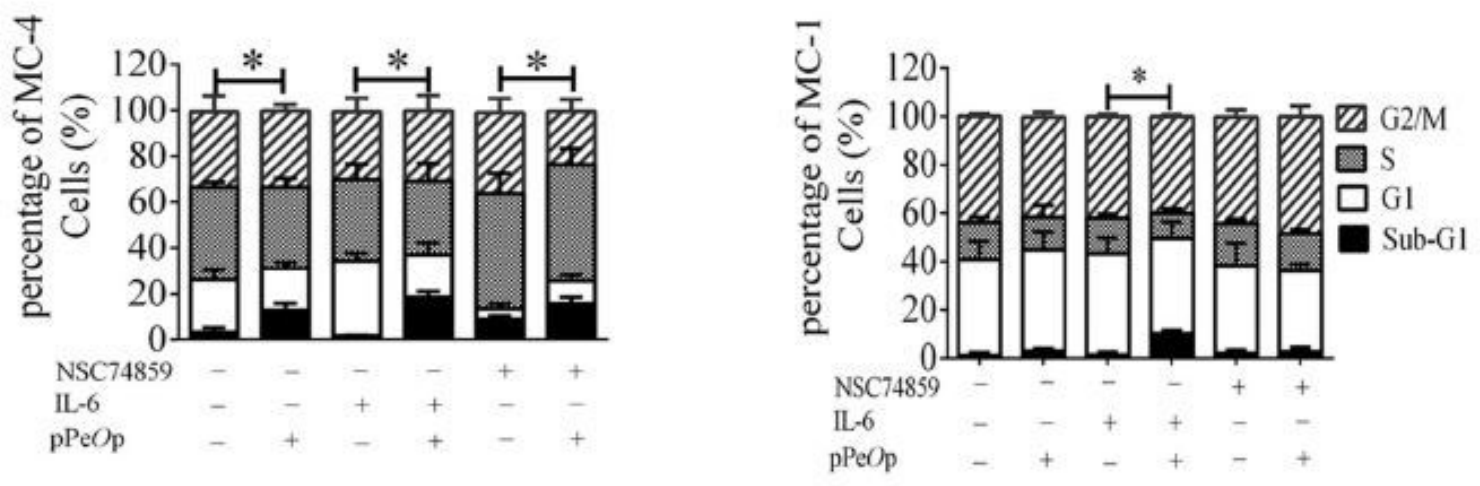

Figure 4

Effects of pPeOp on viability and DNA contents of different phase cells in human gastric cancer cells and human gastric cells. a Cell viability tested by MTS assay. b \& c DNA contents of different phase cells analyzed by flow cytometry. b MC-4 and c MC- 1 cells were treated with pPeOp $(60 \mu \mathrm{g} / \mathrm{ml})$ for $24 \mathrm{~h}$ in the absence or presence of NSC74859 $(100 \mathrm{ng} / \mathrm{ml})$ or IL-6 $(100 \mathrm{ng} / \mathrm{ml})$. d Statistical analysis results of flow cytometry. Results are expressed as mean \pm SD from three separate experiments. ${ }^{*} P<0.05$ vs. control group or as indicated. 
A
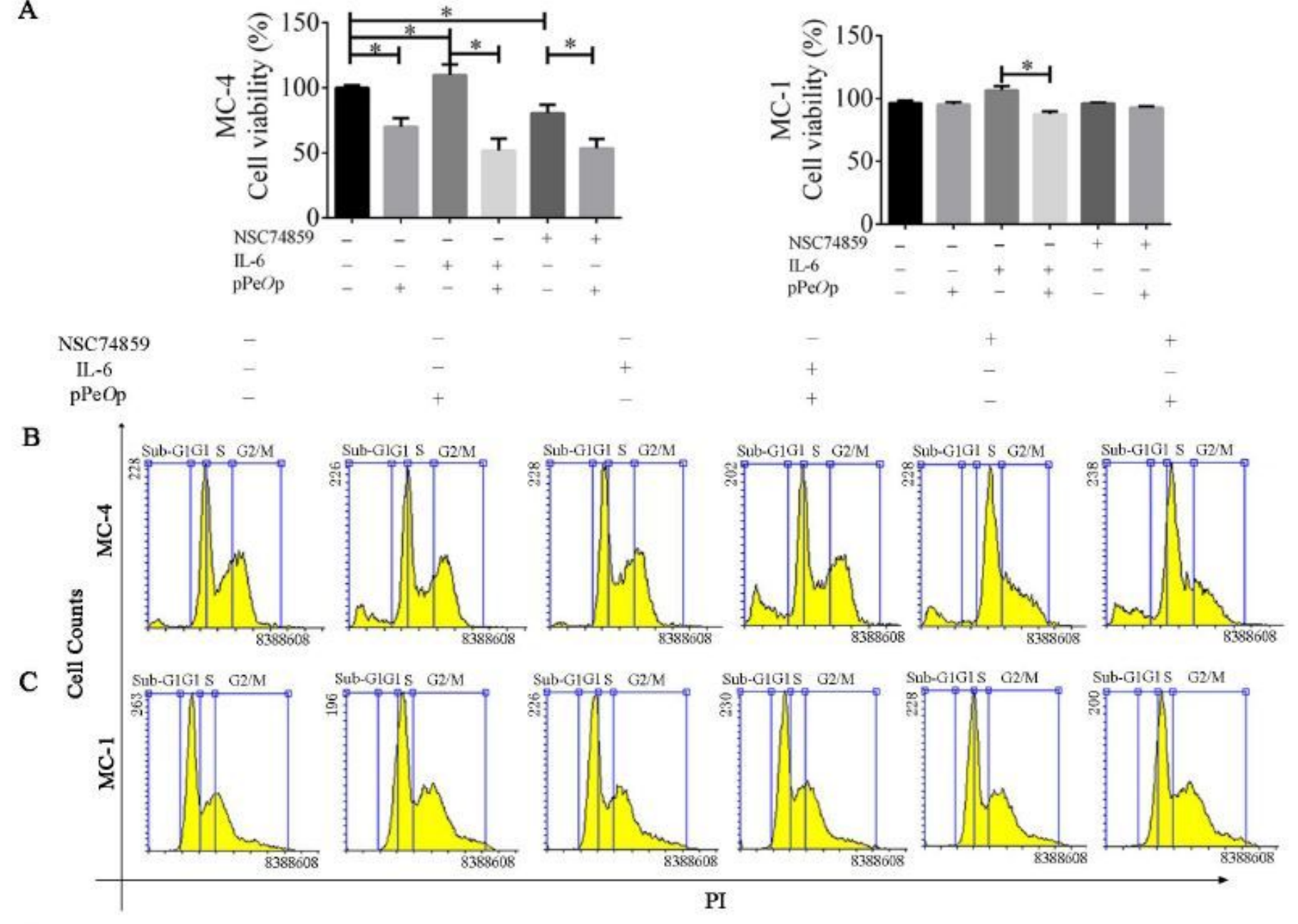

D
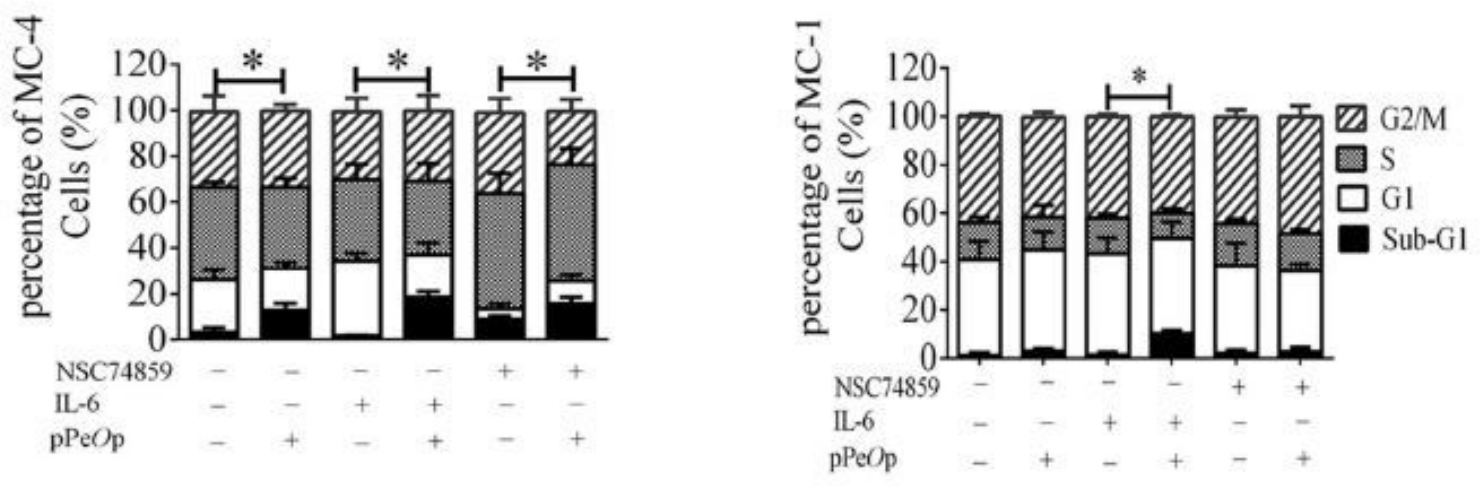

Figure 4

Effects of pPeOp on viability and DNA contents of different phase cells in human gastric cancer cells and human gastric cells. a Cell viability tested by MTS assay. b \& c DNA contents of different phase cells analyzed by flow cytometry. b MC-4 and c MC- 1 cells were treated with pPeOp $(60 \mu \mathrm{g} / \mathrm{ml})$ for $24 \mathrm{~h}$ in the absence or presence of NSC74859 $(100 \mathrm{ng} / \mathrm{ml})$ or IL-6 $(100 \mathrm{ng} / \mathrm{ml})$. d Statistical analysis results of flow cytometry. Results are expressed as mean \pm SD from three separate experiments. ${ }^{*} P<0.05$ vs. control group or as indicated. 
A
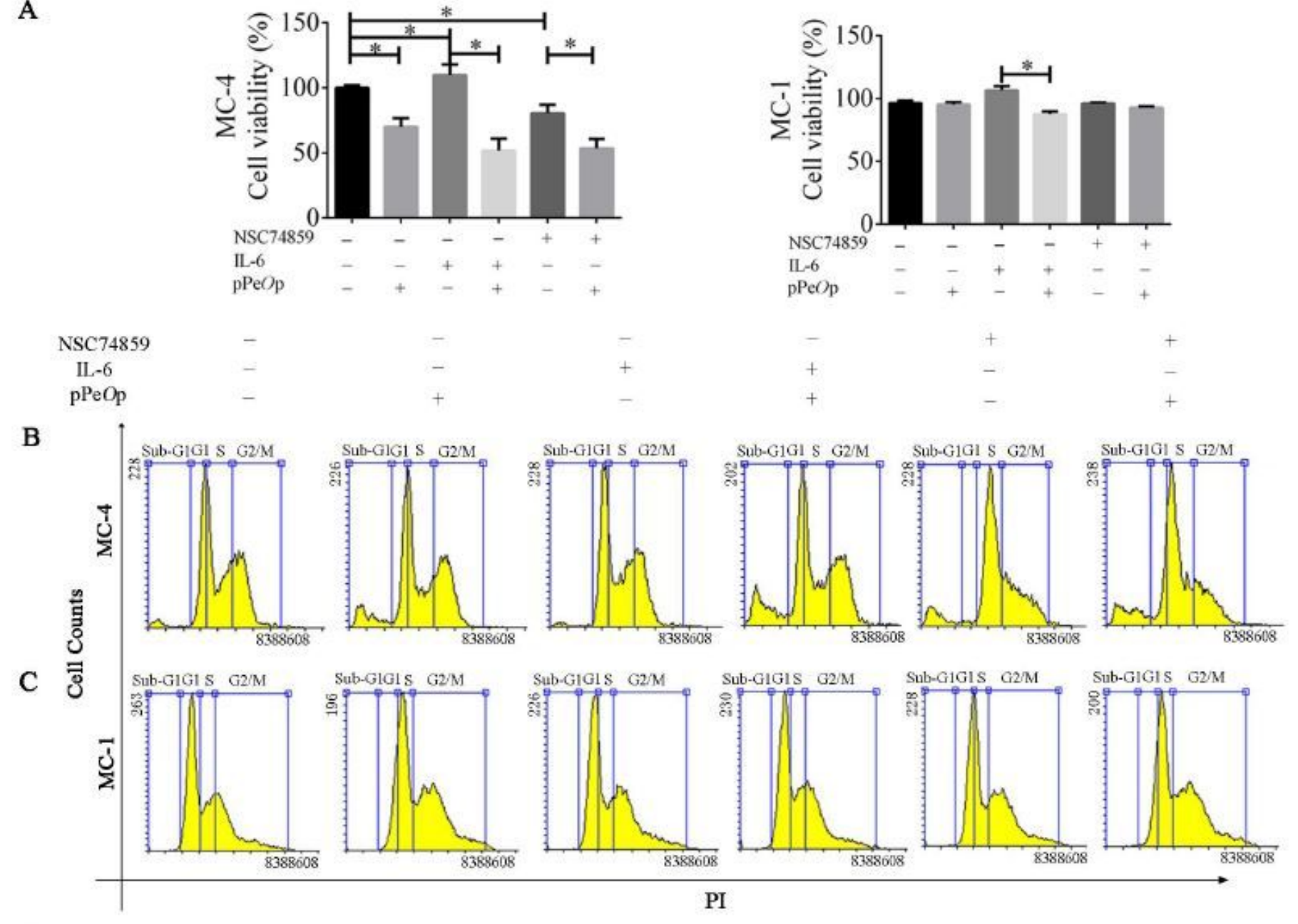

D
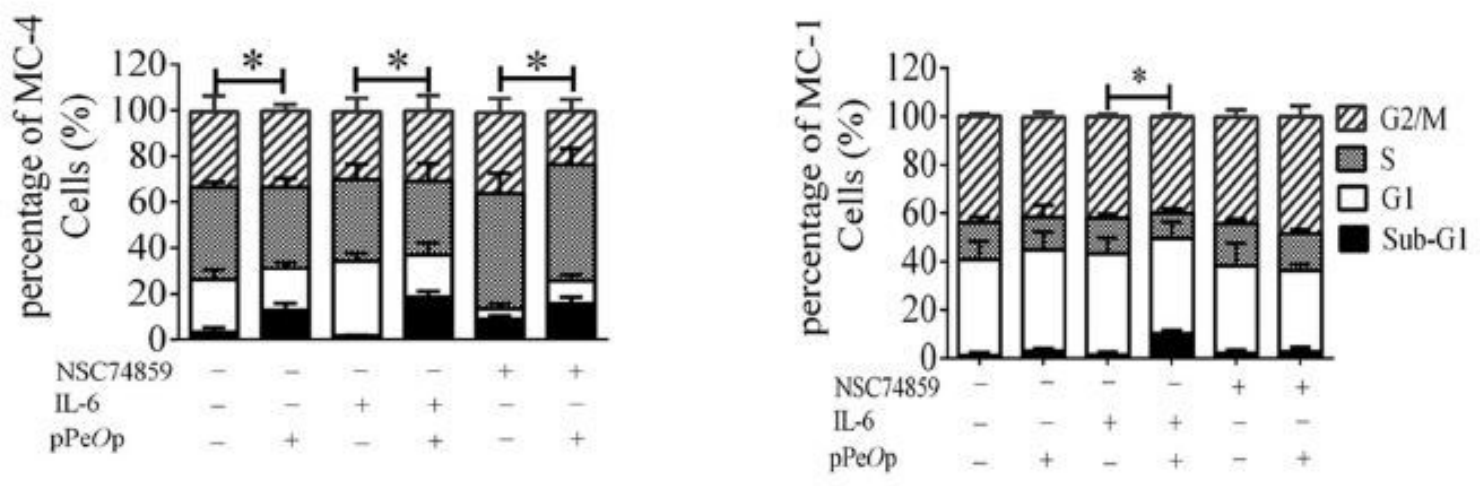

Figure 4

Effects of pPeOp on viability and DNA contents of different phase cells in human gastric cancer cells and human gastric cells. a Cell viability tested by MTS assay. b \& c DNA contents of different phase cells analyzed by flow cytometry. b MC-4 and c MC- 1 cells were treated with pPeOp $(60 \mu \mathrm{g} / \mathrm{ml})$ for $24 \mathrm{~h}$ in the absence or presence of NSC74859 $(100 \mathrm{ng} / \mathrm{ml})$ or IL-6 $(100 \mathrm{ng} / \mathrm{ml})$. d Statistical analysis results of flow cytometry. Results are expressed as mean \pm SD from three separate experiments. ${ }^{*} P<0.05$ vs. control group or as indicated. 
A

NSC74859

IL-6

$\mathrm{pPeOp}$

JAK1

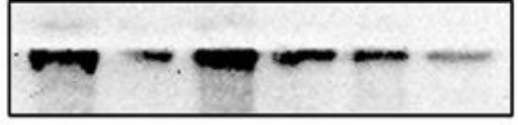

JAK2

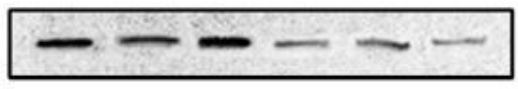

P-STAT3

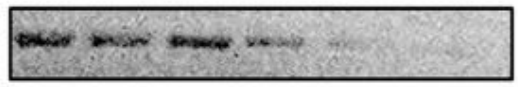

STAT3

SOCS1

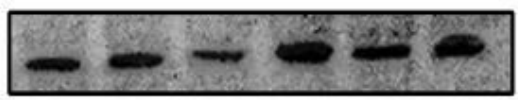

SOCs 3

GAPDH
B
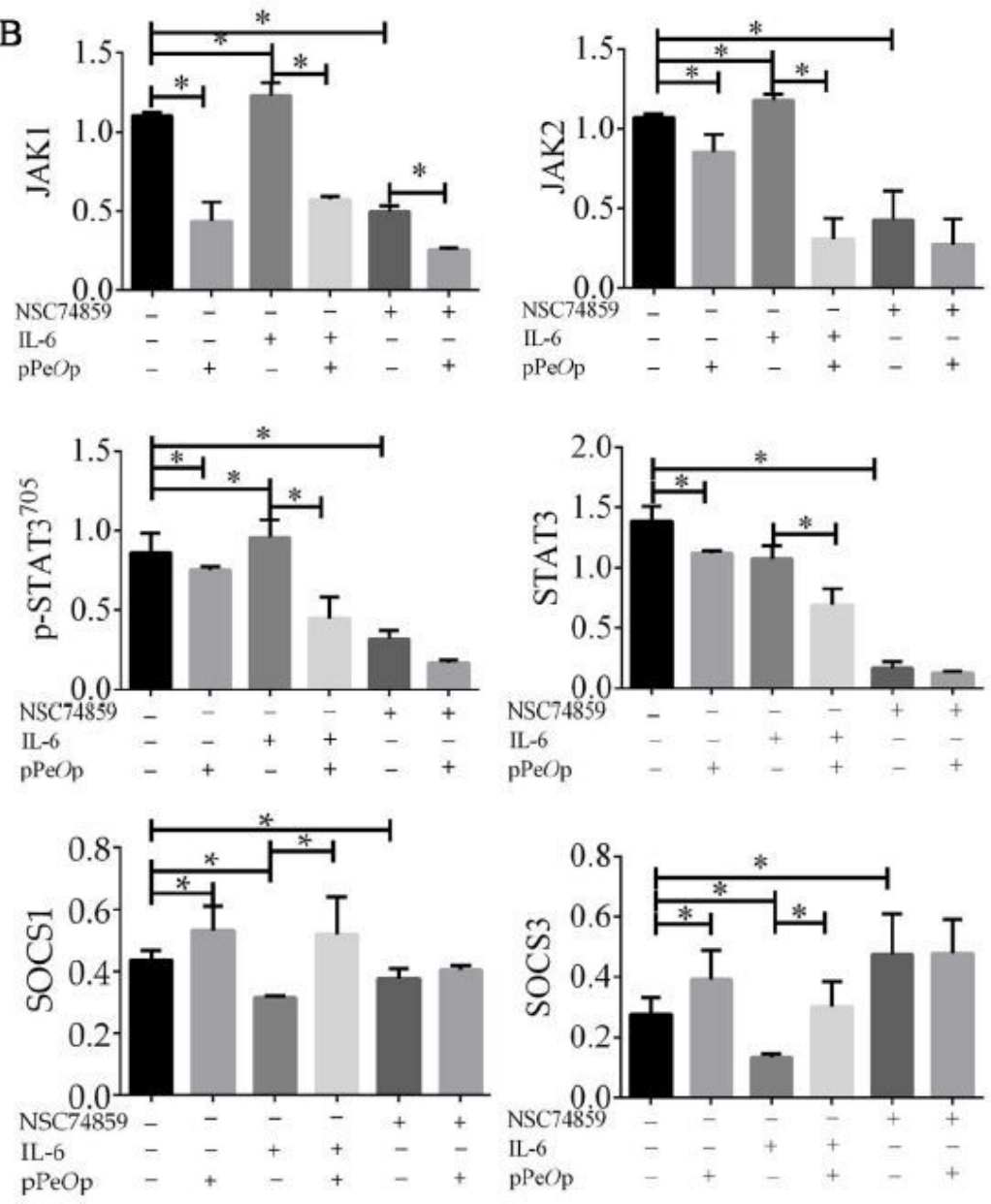

\section{Figure 5}

Effect of pPeOp on the JAK/STAT3 signaling pathway in gastric cancer cells. MC-4 gastric cancer cells were treated with pPeOp $(60 \mu \mathrm{g} / \mathrm{ml})$ in the absence or presence of NSC74859 $(100 \mathrm{ng} / \mathrm{ml})$ or IL-6 (100 $\mathrm{ng} / \mathrm{ml}$ ) for $24 \mathrm{~h}$. a Western blotting was used for detecting the protein expression levels of JAK1, JAK2, STAT3, p-STAT3, SOCS1 and SOCS3. b Results are showed express as mean \pm SD from three separate experiments. ${ }^{*}<0.05$ vs. control group or as indicated. Full-length blots are presented in Supplementary Figure 5. 
A

NSC74859

IL-6

$\mathrm{pPeOp}$

JAK1

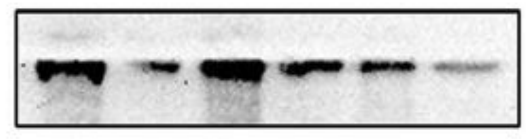

JAK2

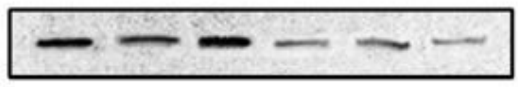

P-STAT3

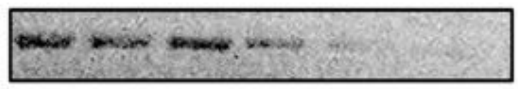

STAT3

SOCS1

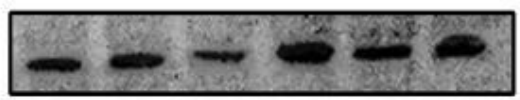

socs 3

GAPDH
B
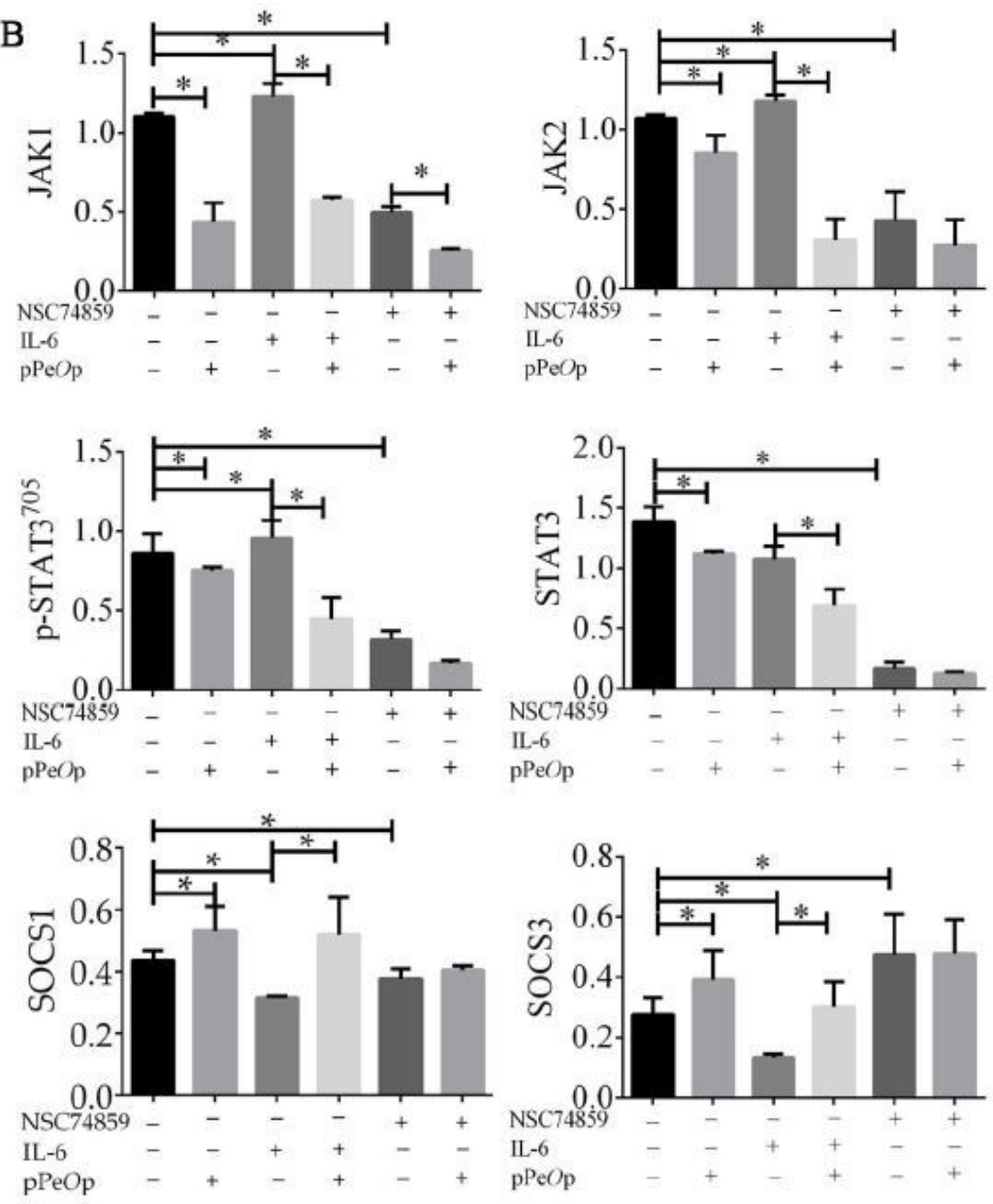

\section{Figure 5}

Effect of pPeOp on the JAK/STAT3 signaling pathway in gastric cancer cells. MC-4 gastric cancer cells were treated with pPeOp $(60 \mu \mathrm{g} / \mathrm{ml})$ in the absence or presence of NSC74859 $(100 \mathrm{ng} / \mathrm{ml})$ or IL-6 $(100$ $\mathrm{ng} / \mathrm{ml}$ ) for $24 \mathrm{~h}$. a Western blotting was used for detecting the protein expression levels of JAK1, JAK2, STAT3, p-STAT3, SOCS1 and SOCS3. b Results are showed express as mean \pm SD from three separate experiments. ${ }^{*}<0.05$ vs. control group or as indicated. Full-length blots are presented in Supplementary Figure 5. 
A

NSC74859

IL-6

$\mathrm{pPeOp}$

JAK1

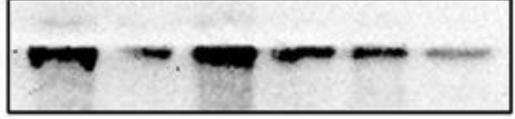

JAK2

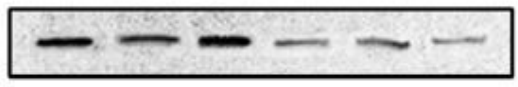

P-STAT3

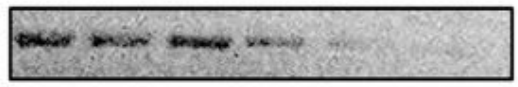

STAT3

SOCS1

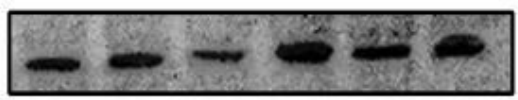

SOCs 3

GAPDH
B
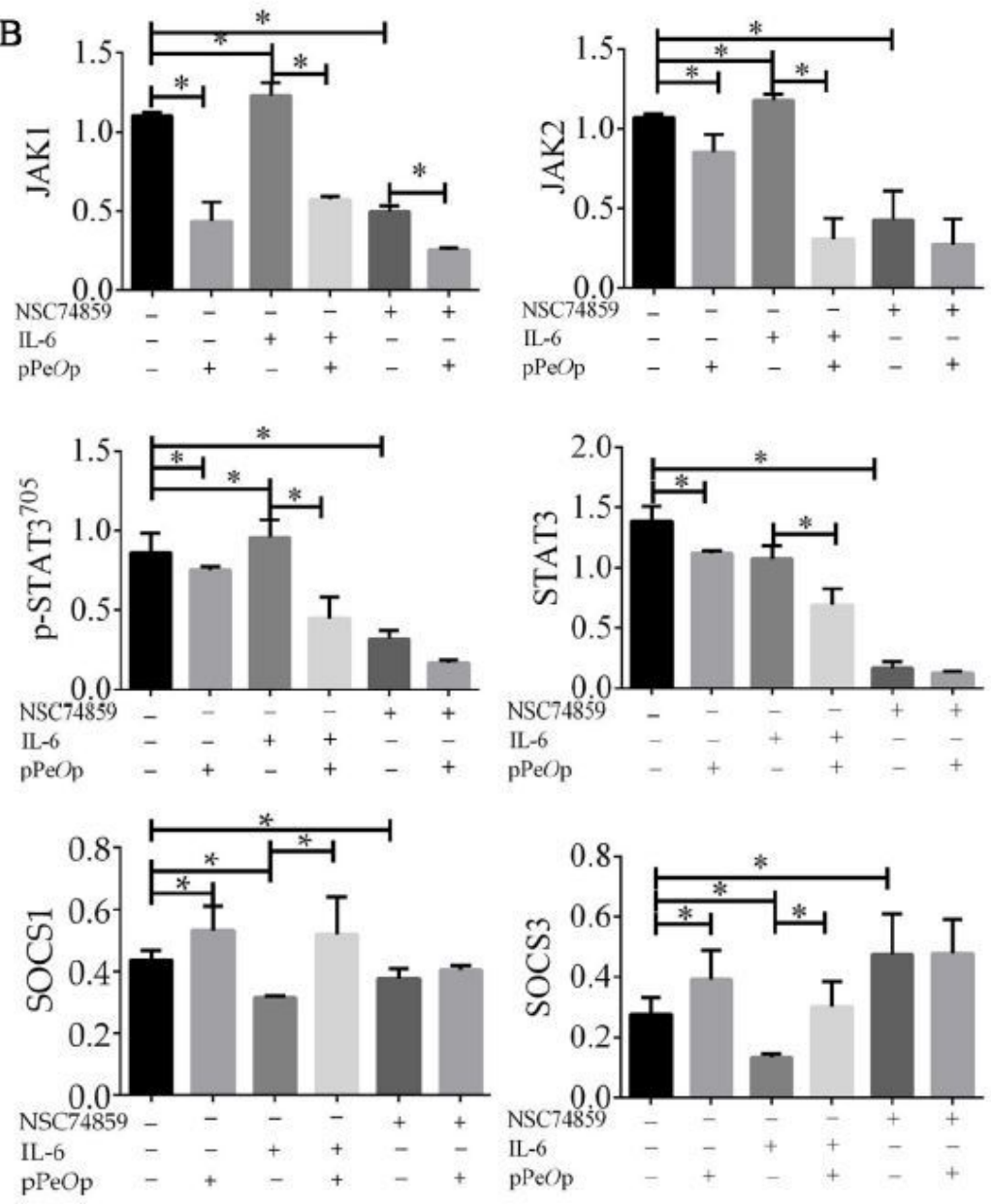

\section{Figure 5}

Effect of pPeOp on the JAK/STAT3 signaling pathway in gastric cancer cells. MC-4 gastric cancer cells were treated with pPeOp $(60 \mu \mathrm{g} / \mathrm{ml})$ in the absence or presence of NSC74859 $(100 \mathrm{ng} / \mathrm{ml})$ or IL-6 (100 $\mathrm{ng} / \mathrm{ml}$ ) for $24 \mathrm{~h}$. a Western blotting was used for detecting the protein expression levels of JAK1, JAK2, STAT3, p-STAT3, SOCS1 and SOCS3. b Results are showed express as mean \pm SD from three separate experiments. ${ }^{*}<0.05$ vs. control group or as indicated. Full-length blots are presented in Supplementary Figure 5. 


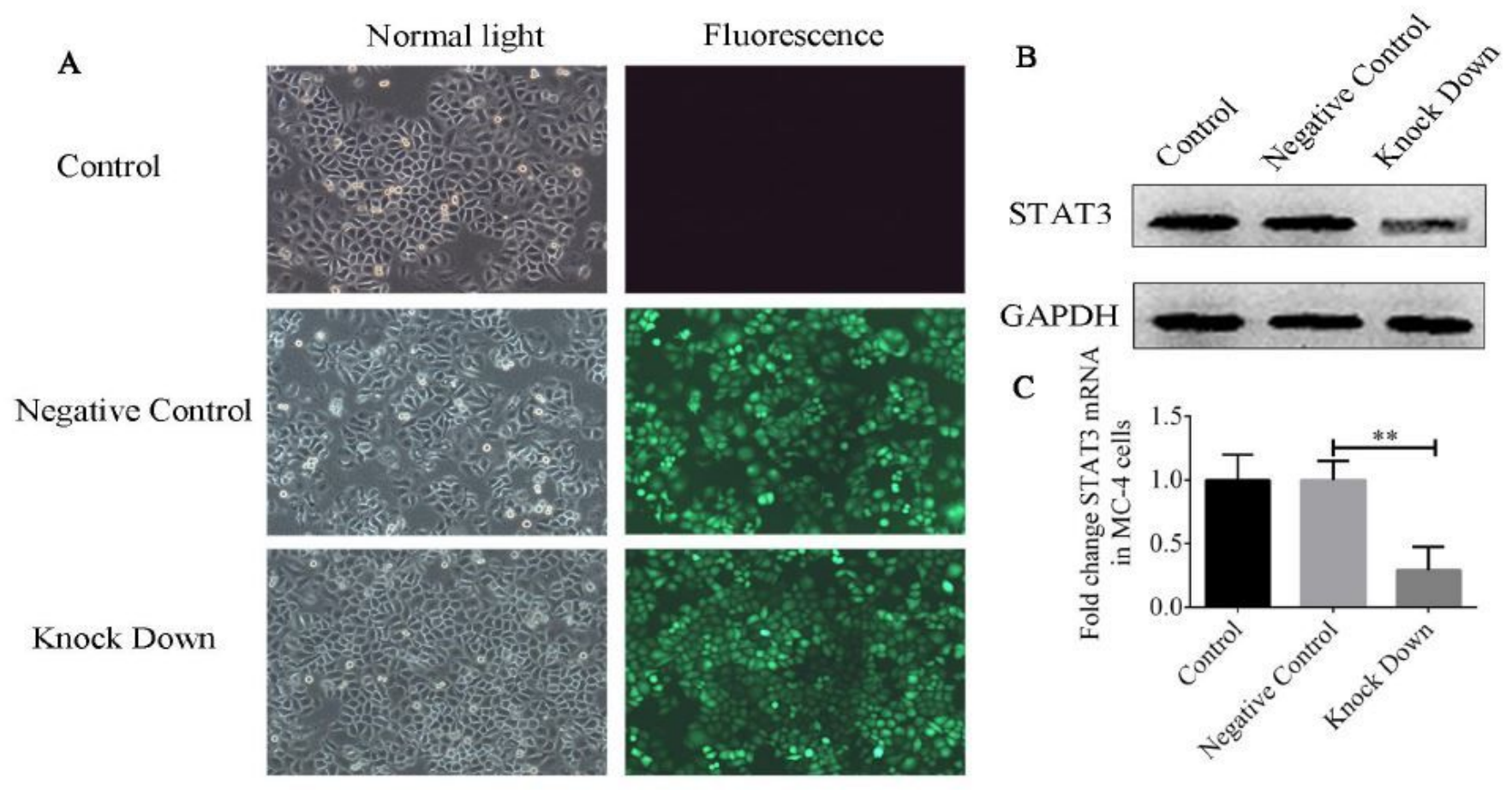

\section{Figure 6}

MC-4 gastric cancer cells were transfected by lentivirus. a Cell morphology under normal light and fluorescence (20x). b STAT3 protein expression was detected by western blotting. c STAT3 gene expression in MC-4 cells was detected by RT-qPCR after transfected by lentivirus. Results are showed express as mean \pm SD from three separate experiments. ${ }^{*} \mathrm{P}<0.01$ vs. negative control group. Full-length blots are presented in Supplementary Figure 6. 

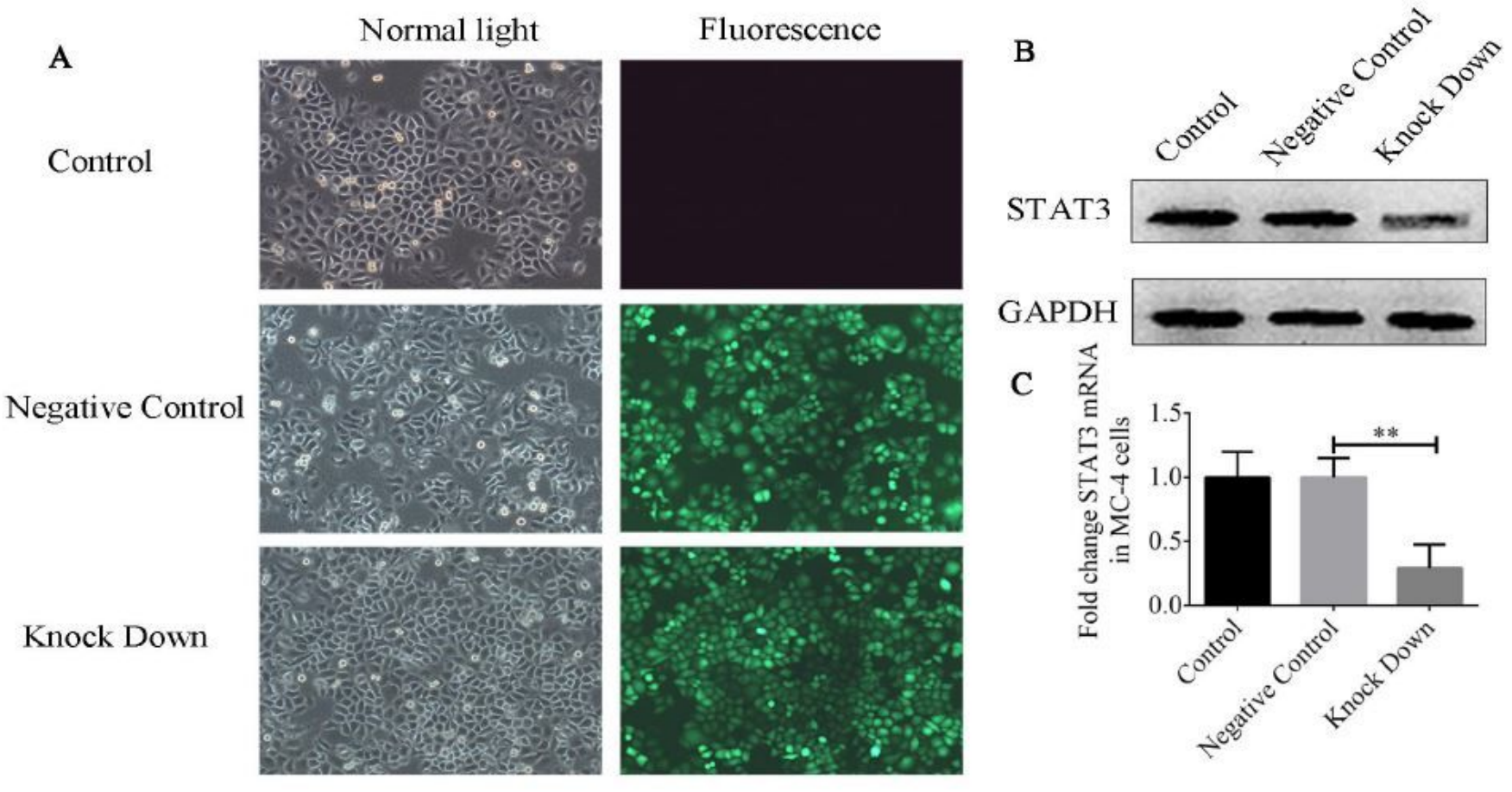

\section{Figure 6}

MC-4 gastric cancer cells were transfected by lentivirus. a Cell morphology under normal light and fluorescence (20x). b STAT3 protein expression was detected by western blotting. c STAT3 gene expression in MC-4 cells was detected by RT-qPCR after transfected by lentivirus. Results are showed express as mean \pm SD from three separate experiments. ${ }^{*} \mathrm{P}<0.01$ vs. negative control group. Full-length blots are presented in Supplementary Figure 6. 

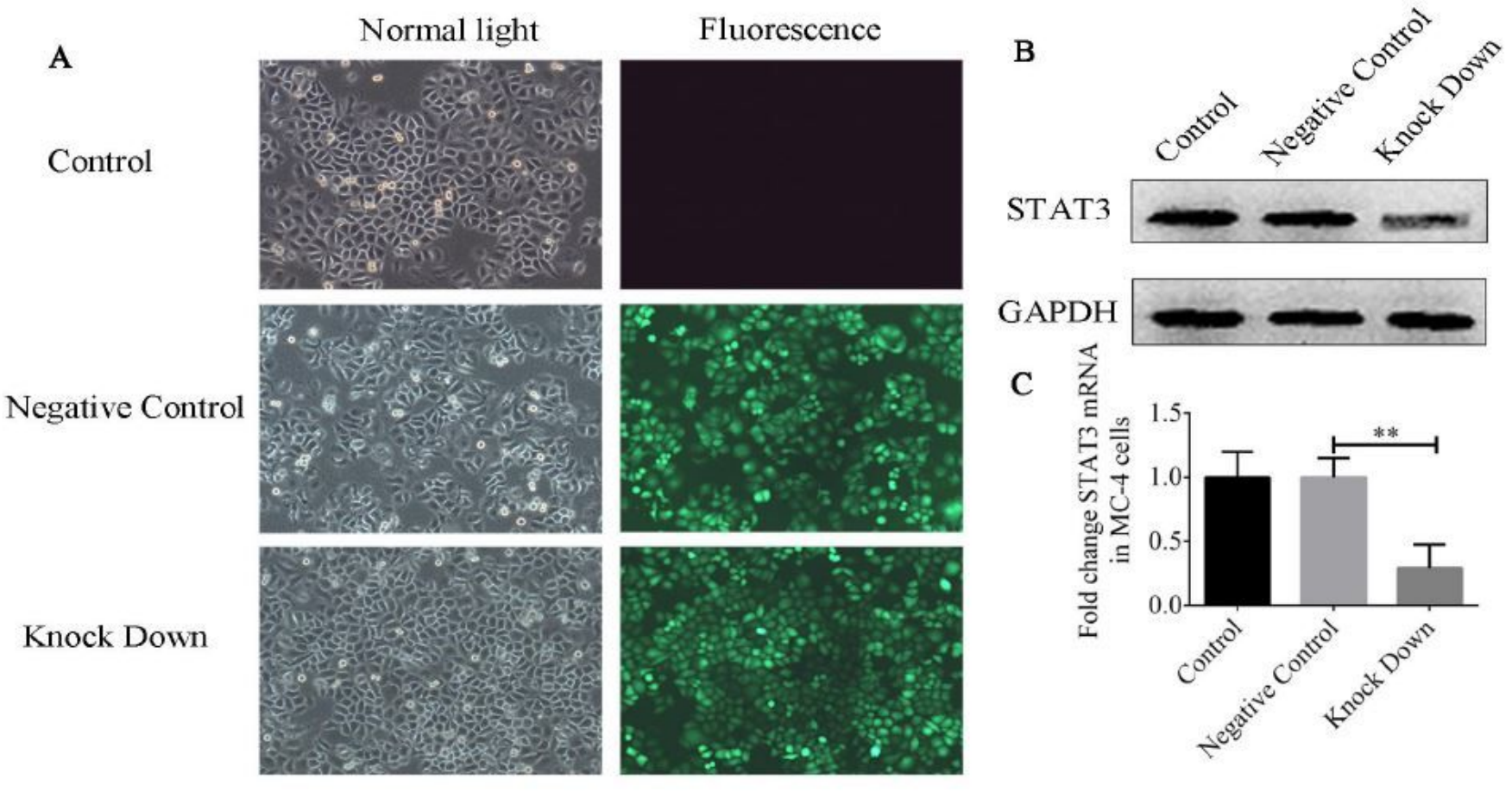

\section{Figure 6}

MC-4 gastric cancer cells were transfected by lentivirus. a Cell morphology under normal light and fluorescence (20x). b STAT3 protein expression was detected by western blotting. c STAT3 gene expression in MC-4 cells was detected by RT-qPCR after transfected by lentivirus. Results are showed express as mean \pm SD from three separate experiments. ${ }^{*} \mathrm{P}<0.01$ vs. negative control group. Full-length blots are presented in Supplementary Figure 6. 
A

NC KD pPeOp

$+\quad-\quad-$

$+\quad+\quad+$

$+\quad+$

\section{B NC+PVP}

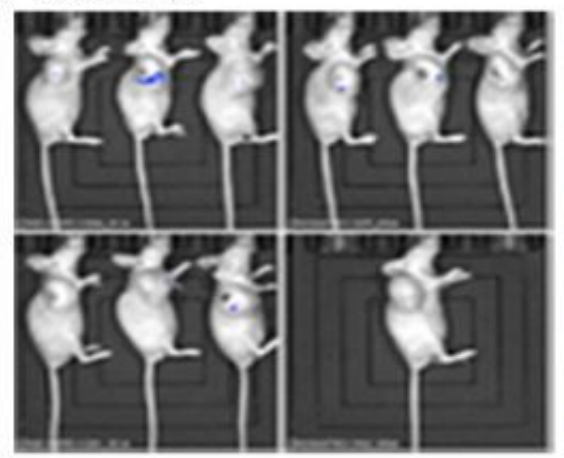

$\mathrm{D}$ KD+PVP

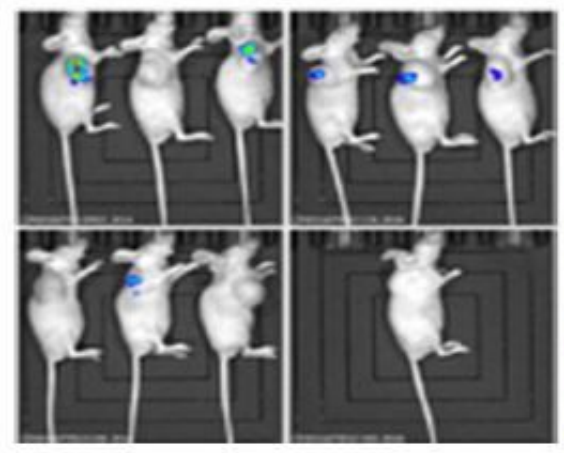

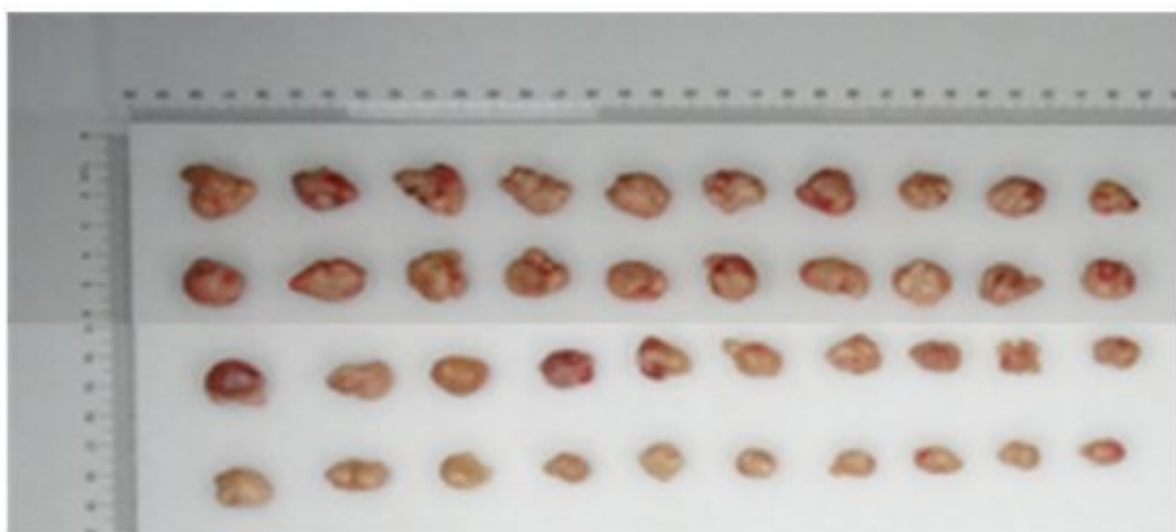

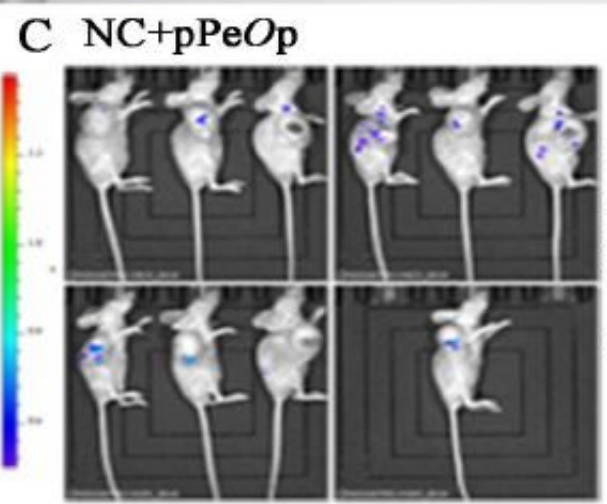

$\mathrm{F}$

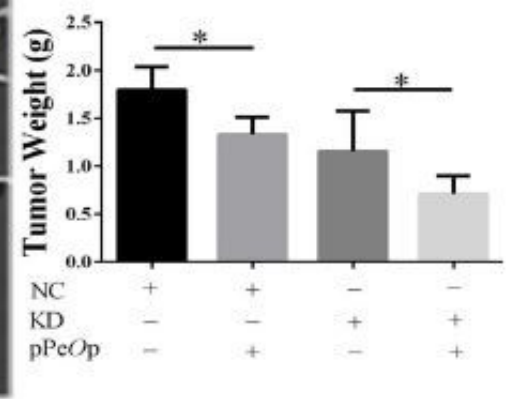

$\mathrm{E} \mathrm{KD}+\mathrm{pPeOp}$

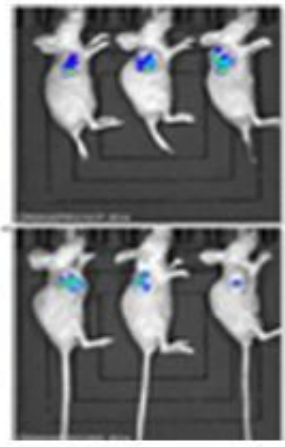

G

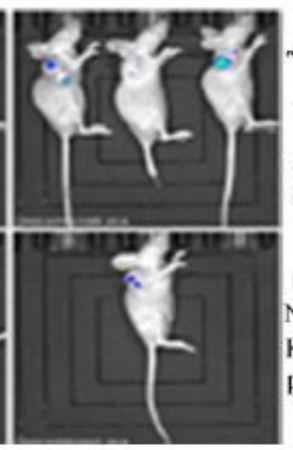

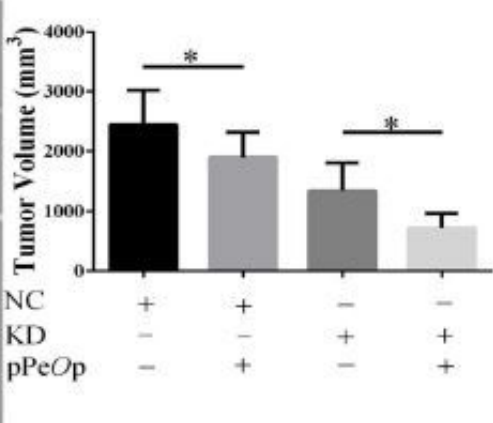

\section{Figure 7}

Anticancer effects of pPeOp in xenograft nude mice. a PVP $(10 \mathrm{mg} / \mathrm{kg})$ or pPeOp $(10 \mathrm{mg} / \mathrm{kg})$ were treated via tail vein injection every 5 days. Tumors were excised out of the mice at day 25 . b \& c The living images of nude mice in negative control group, which being treated with PVP ( $10 \mathrm{mg} / \mathrm{kg}, 10$ nude mice in Fig. 7B) and pPeOp (10 mg/kg, 10 nude mice in Fig. 7C), respectively. $\mathrm{d}$ \& e The living images of nude mice in STAT3 knock down group, which being treated with PVP $(10 \mathrm{mg} / \mathrm{kg}, 10$ nude mice in Fig. 7D) and pPeOp (10 mg/kg, 10 nude mice in Fig. 7E), respectively. $f$ Tumor weight of different groups of nude mice. $g$ Tumor volume of different groups of nude mice. Results are showed express as mean $\pm S D \llbracket n=10$. ${ }^{*}<$ 0.05 vs. NC group or as indicated. 
A

NC KD pPeOp

$+\quad-\quad-$

$+\quad-\quad+$

- + -

B NC+PVP

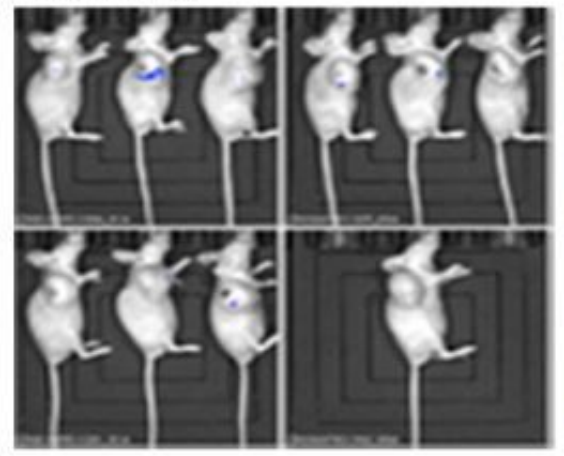

$\mathrm{D}$ KD+PVP

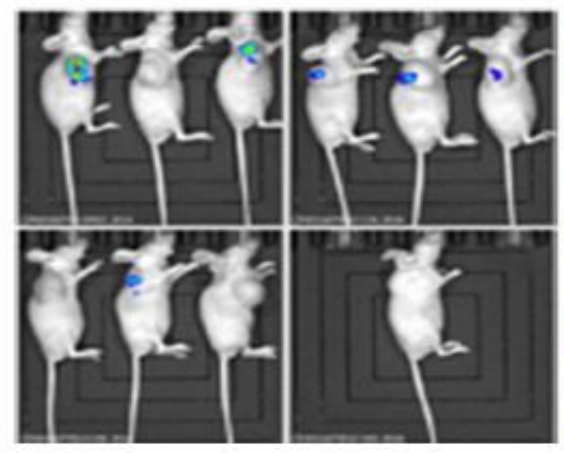

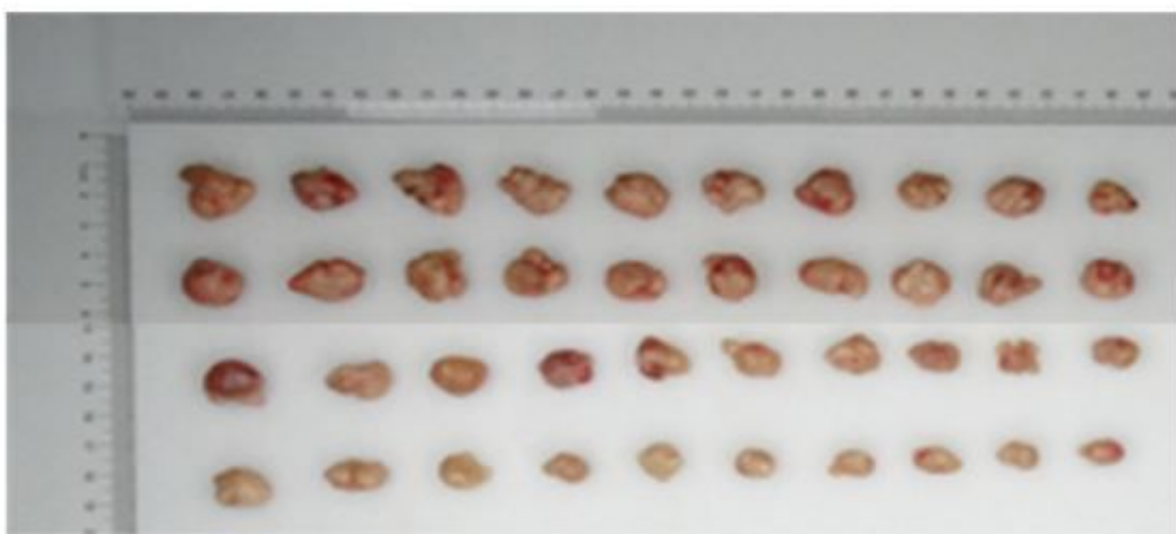

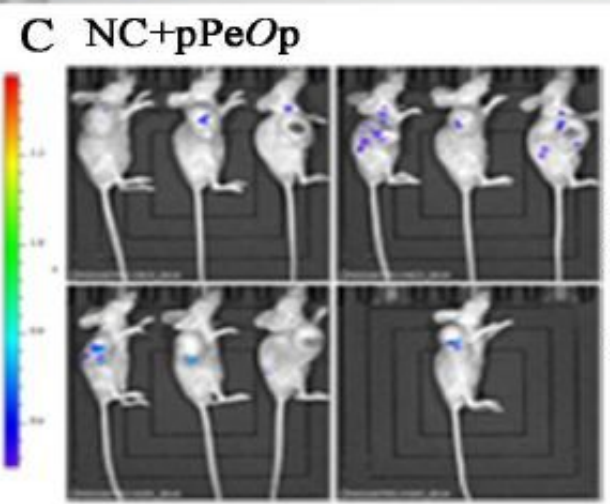

$\mathrm{F}$

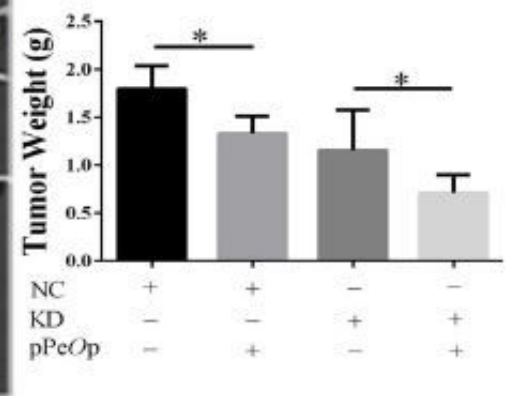

$\mathrm{E} \mathrm{KD}+\mathrm{pPeOp}$

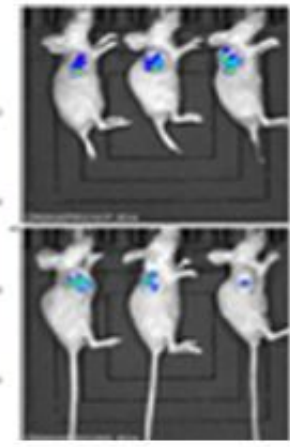

G
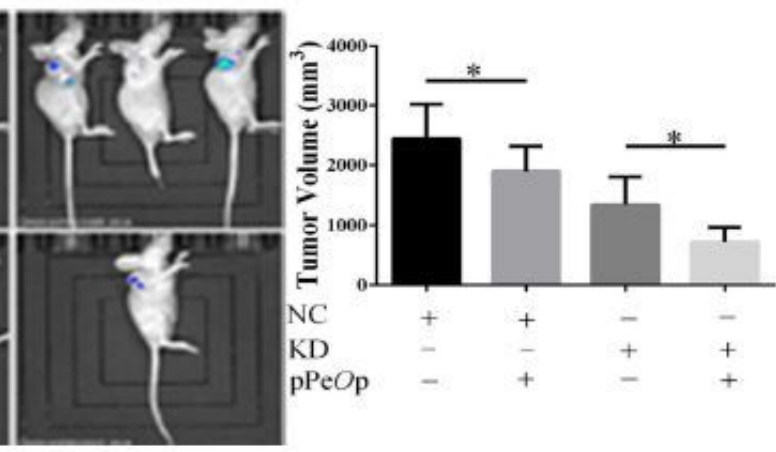

\section{Figure 7}

Anticancer effects of pPeOp in xenograft nude mice. a PVP $(10 \mathrm{mg} / \mathrm{kg})$ or pPeOp $(10 \mathrm{mg} / \mathrm{kg})$ were treated via tail vein injection every 5 days. Tumors were excised out of the mice at day 25 . b \& c The living images of nude mice in negative control group, which being treated with PVP ( $10 \mathrm{mg} / \mathrm{kg}, 10$ nude mice in Fig. 7B) and pPeOp (10 mg/kg, 10 nude mice in Fig. 7C), respectively. $\mathrm{d}$ \& e The living images of nude mice in STAT3 knock down group, which being treated with PVP $(10 \mathrm{mg} / \mathrm{kg}, 10$ nude mice in Fig. 7D) and pPeOp (10 mg/kg, 10 nude mice in Fig. 7E), respectively. $f$ Tumor weight of different groups of nude mice. $g$ Tumor volume of different groups of nude mice. Results are showed express as mean $\pm S D \llbracket n=10$. ${ }^{*}<$ 0.05 vs. NC group or as indicated. 
A

NC KD pPeOp

$+\quad-\quad-$

$+\quad-\quad+$

- + -

B NC+PVP

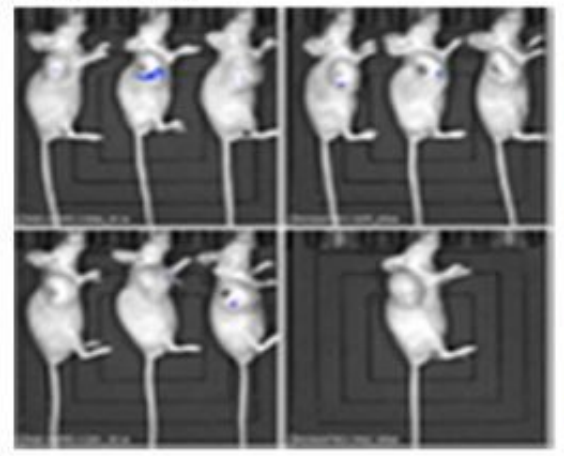

$\mathrm{D}$ KD+PVP

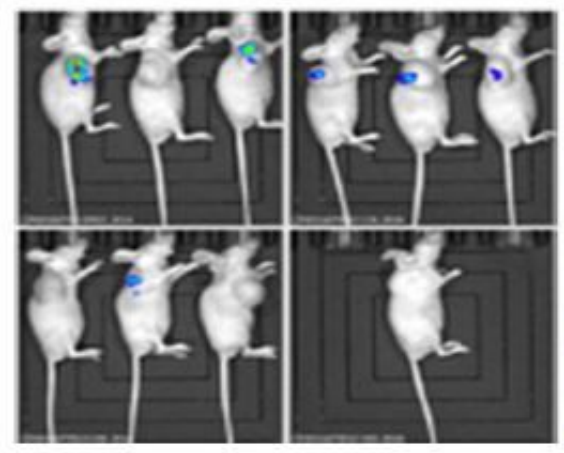

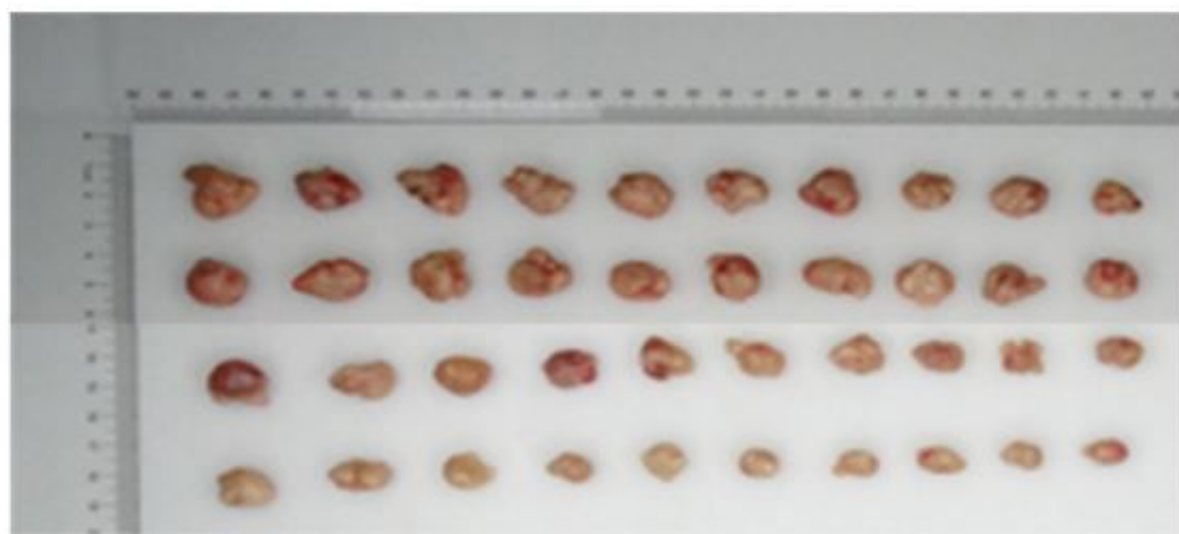

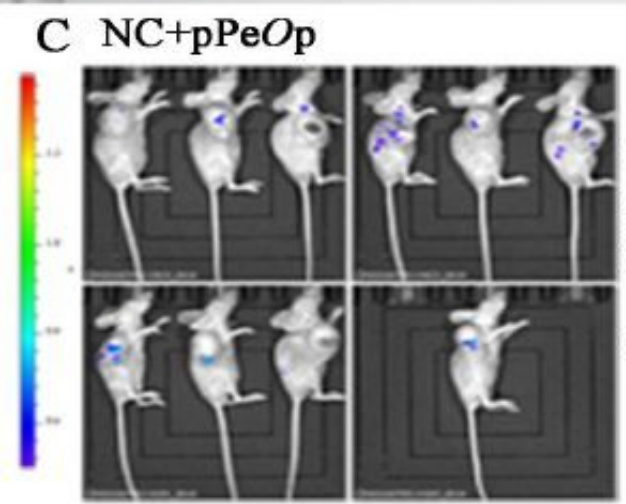

$\mathrm{F}$

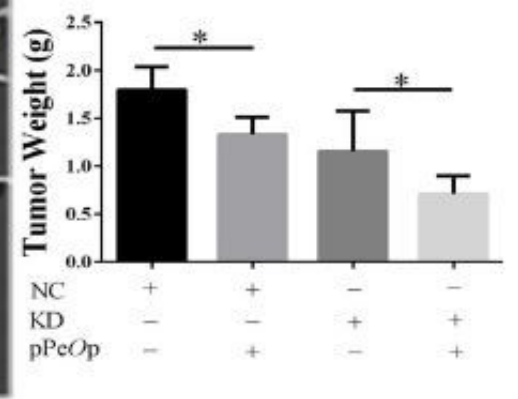

$\mathrm{E} \mathrm{KD}+\mathrm{pPeOp}$

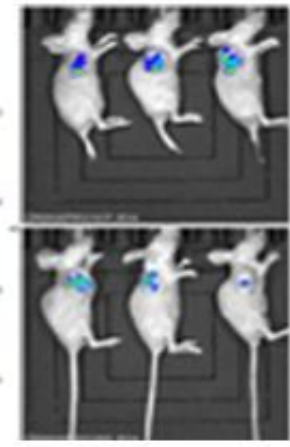

G

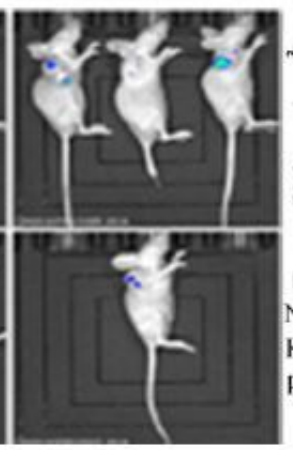

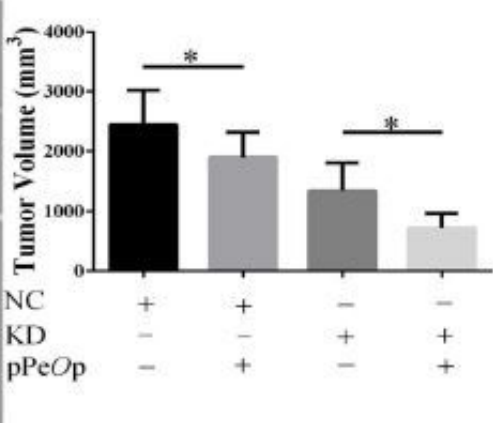

\section{Figure 7}

Anticancer effects of pPeOp in xenograft nude mice. a PVP $(10 \mathrm{mg} / \mathrm{kg})$ or pPeOp $(10 \mathrm{mg} / \mathrm{kg})$ were treated via tail vein injection every 5 days. Tumors were excised out of the mice at day 25 . b \& c The living images of nude mice in negative control group, which being treated with PVP ( $10 \mathrm{mg} / \mathrm{kg}, 10$ nude mice in Fig. 7B) and pPeOp (10 mg/kg, 10 nude mice in Fig. 7C), respectively. $\mathrm{d}$ \& e The living images of nude mice in STAT3 knock down group, which being treated with PVP $(10 \mathrm{mg} / \mathrm{kg}, 10$ nude mice in Fig. 7D) and pPeOp (10 mg/kg, 10 nude mice in Fig. 7E), respectively. $f$ Tumor weight of different groups of nude mice. $g$ Tumor volume of different groups of nude mice. Results are showed express as mean $\pm S D \llbracket n=10$. ${ }^{*}<$ 0.05 vs. NC group or as indicated.

\section{Supplementary Files}


This is a list of supplementary files associated with this preprint. Click to download.

- TitlePageandTheOriginalFiguresofWesternBlot.docx

- TitlePageandTheOriginalFiguresofWesternBlot.docx

- TitlePageandTheOriginalFiguresofWesternBlot.docx 